\title{
Non-alcoholic fatty liver disease in adults 2021: A clinical practice guideline of the Italian Association for the Study of the Liver (AISF), the Italian Society of Diabetology (SID) and the Italian Society of Obesity (SIO)
}

\author{
Associazione Italiana per lo Studio del Fegato (AISF), Società Italiana di Diabetologia (SID) and Società Italiana \\ dell'Obesità (SIO) ${ }^{1}$
}

Received: 23 March 2021 / Accepted: 29 July 2021 / Published online: 16 December 2021

(c) The Author(s) 2021. This is an open access article under the CC-BY-NC-ND license (https://creativecommons.org/licenses/by-nc-nd/4.0/) 2021

\begin{abstract}
Nonalcoholic fatty liver disease (NAFLD) is a common and emerging liver disease in adults, paralleling the epidemic of obesity and diabetes and leading to worrisome events (hepatocellular carcinoma and end-stage liver disease). In the past years, mounting evidence added insights about epidemiology, natural history, diagnosis and lifestyle-based or drug treatment of NAFLD. In this rapidly evolving scenario, members of the Associazione Italiana per lo Studio del Fegato, the Società Italiana di Diabetologia and the Società Italiana dell'Obesità reviewed current knowledge on NAFLD. The quality of the published evidence is graded, and practical recommendations are made following the rules and the methodology suggested in Italy by the Centro Nazionale per l'Eccellenza delle cure and Istituto Superiore di Sanità. Whenever possible, recommendations are placed within the context the Italian Healthcare system, with reference to specific experience and local diagnostic and management resources.

Level of evidence Level of evidence of recommendations for each PICO question were reported according to available evidence.
\end{abstract}

Keywords NAFLD $\cdot$ NASH $\cdot$ Guidelines

\section{Introduction}

The present report is a summary of Clinical Practice Guidelines resulting from a cooperative work of the Associazione Italiana per lo Studio del Fegato (AISF), the Società Italiana

The members of the guidelines panel are listed in Appendix 2.

Correspondence:

S. Petta

E-mail addresses: info@webasif.org, salvatore.petta@unipa.it

This article is co-published in the journals: Digestive and Liver Disease (https://doi.org/10.1016/j.dld.2021.04.029); Nutrition, Metabolism \& Cardiovascular Diseases (https://doi.org/10.1016/j. numecd.2021.04.028) and Eating and Weight Disorders - Studies on Anorexia, Bulimia and Obesity (https://doi.org/10.1007/ s40519-021-01287-1).

Associazione Italiana per lo Studio del Fegato (AISF), Società Italiana di Diabetologia (SID) and Società Italiana dell'Obesità (SIO)

1 University of Palermo, Palermo, Italy di Diabetologia (SID) and the Società Italiana dell'Obesità (SIO). Current knowledge on the diagnosis and treatment of non-alcoholic fatty liver disease (NAFLD) is translated into relevant practical recommendations for management following the rules and the methodology suggested in Italy by the Centro Nazionale per l'Eccellenza delle cure (CNEC) and Istituto Superiore di Sanità (ISS). In this summary, we report the outline of disease burden and the risks associated with disease progression, followed by PICO questions and recommendations. The review of the literature at the basis of individual recommendations is uploaded as supplementary material.

\section{Burden of disease and risk factors}

The natural history of nonalcoholic fatty liver disease (NAFLD) has been extensively investigated in the past 20 years [1,2]. Steatosis is the hallmark of NAFLD and has been identified as an independent risk factor for the full spectrum of liver damage including inflammation, 
ballooning and fibrosis [3]. The diagnosis of NAFLD requires the exclusion of both secondary causes and of alcohol consumption $\geq 30 \mathrm{~g} /$ day for men and $\geq 20 \mathrm{~g} /$ day for women [4]. Recently, a consensus of experts proposed to overcome the current nomenclature "NAFLD" and adopt for a "positive" definition the acronym "Metabolic dysfunction-Associated Fatty Liver Disease (MAFLD)" using metabolic dysfunctions as diagnostic criteria independently of the presence of other causes of chronic liver disease [5]. The mean prevalence of NAFLD worldwide is $24.1 \%$, ranging from $13.5 \%$ in Africa to $31.8 \%$ in Middle East, with differences among studies also related to diagnostic methods, age, gender and ethnicity [1]. Italian studies indicate a prevalence of $22.5-27.0 \%$ in the general population [6-9], with a $2 \%$ prevalence of noninvasively assessed advanced fibrosis due to NAFLD [9]. The prevalence increases in patients with metabolic comorbidities and the metabolic syndrome (MetS), defined by the presence of at least three metabolic alterations among elevated waist circumference $(\geq 94 \mathrm{~cm}$ in males; $\geq 80 \mathrm{~cm}$ in females in Europids), elevated triglycerides $(\geq 150 \mathrm{mg} / \mathrm{dL})$, reduced HDL-C $(<40 \mathrm{mg} / \mathrm{dL}$ in males; $<50 \mathrm{mg} / \mathrm{dL}$ in females), elevated blood pressure (systolic pressure $\geq 130 \mathrm{mmHg}$ and/or diastolic pressure $\geq 85 \mathrm{~mm}$ or antihypertensive drug treatment) and elevated fasting glucose $(\geq 100 \mathrm{mg} / \mathrm{dL}$ antihyperglycemic treatment) [10]. NAFLD is observed in 54-90\% [9, 11] and $78.8 \%$ [12] of cases with obesity or with MetS, respectively. In the Dionysos study, the presence of steatosis was closely associated with obesity [13] and in the Dionysos and Nutrition Liver Study the risk of NAFLD was ninefold increased by the presence of BMI $\geq 30 \mathrm{~kg} / \mathrm{m}^{2}$ and sixfold by abdominal obesity (waist circumference $\geq 102 \mathrm{~cm}$ in males, $\geq 88$ in females)[6], independently of altered liver enzymes. Raised liver enzymes, assumed as surrogate indexes of NAFLD, were reported in $21 \%$ of cases with obesity and did not increase systematically with obesity class [14]. In a more recent analysis of 890 subjects of the community-based $\mathrm{ABCD}$ ("Alimentazione, Benessere Cardiovascolare e Diabete") study, Petta et al. reported a NAFLD prevalence of $48 \%$, with a relative risk for obesity of 4.02 (95\% confidence interval, 2.77-5.84) [9], but the various diagnostic tools and/or settings may provide slightly different results.

The prevalence of NAFLD is as high as $70-80 \%$ in patients with type 2 diabetes mellitus (T2DM) [15, 16], who are also more likely to have nonalcoholic steatohepatitis (NASH) and cirrhosis, even in the presence of fairly normal serum aminotransferase levels [16-18]. In Italian patients with diabetes NAFLD is reported in 59.0-73.2\% [19, 20], with about $13-18 \%$ of them experiencing advanced fibrosis [21]. A bidirectional association exists between NAFLD and T2DM [17, 22], worsening the course of both diseases; the presence of T2DM increases the risk of NAFLD progression to advanced fibrosis and cirrhosis, as well as also of incident hepatocellular carcinoma (HCC), liver-related hospital admissions and liver-related deaths [17, 23-25], whereas the presence of NAFLD in T2DM is associated with a reduced probability of achieving good glycemic control, and exacerbates atherogenic dyslipidemia, further increasing the risk of chronic kidney disease and adverse CV outcomes [17, 18], particularly in the presence of NASH-fibrosis [26].

The lifetime costs of all NASH patients in the United States in 2017 is estimated at $\$ 222.6$ billion, and the cost of the advanced NASH population at $\$ 95.4$ billion [27]. Data from Italian local Health Units, based on administrative data and resources utilization, calculated an average direct cost for NAFLD/NASH progressively increasing from the nonadvanced stage, to advanced NAFLD disease, compensated cirrhosis, liver transplant, and hepatocellular carcinoma (HCC), also driven by comorbidities, up to over $€ 65,000 /$ year [28]. Considering the projections calculated by disease modelling for the next decades, the total costs is likely to become very challenging for the National Health system [28].

\section{NAFLD mortality and morbidity}

Patients with NAFLD have an increased overall mortality compared to matched control populations [29, 30]. According to a meta-analysis, overall mortality was reported to be 15.4 per 1000 person-years (range 11.7-20.3) for patients with NAFLD and 25.6 (range 6.3-103.8) for the cohort with NASH [1]. The presence of NASH [adjusted hazard ratio ( ${ }_{\text {adj }} \mathrm{HR}$ ) 9.16], age ( ${ }_{\mathrm{adj}} \mathrm{HR} 1.06$ ), and the presence of T2DM $\left({ }_{\text {adj }} H R\right.$ 2.09) increased all-cause and liver-related mortality, after controlling for other variables. Liver-specific mortality was estimated as 0.8 (range 0.3-1.8) in NAFLD and 11.8 (range 7.1-19.5) in NASH [1]. Cardiovascular (CV) disease (CVD) remains the most common cause of death, independent of other metabolic comorbidities [31, 32], driven by the atherogenic profile and widespread $\mathrm{CV}$ complications [32-34], independently of other known risk factors [35, 36]. Fibrosis stage is the strongest predictor for mortality from CVD and liver-related disease in a cohort of biopsy-proven NAFLD after up to 33 years of follow-up [37].

NAFLD is also associated with an approximate twofold increased risk of incident T2DM, ranging from a $35 \%$ to a 5.5 -fold increase, independent of overweight/obesity and other common risk factors $[33,38]$. The risk of incident T2DM appears to diminish over time following the improvement or resolution of NAFLD [39, 40]. Patients with NAFLD also have a nearly $40 \%$ increase in the long-term risk of incident chronic kidney disease [41], as well as other recognized associations with sleep apnea, osteoporosis, psoriasis and endocrinopathies [42]. 
The presence of NASH increases liver-related mortality $[43,44]$, but the most important driver of mortality is fibrosis at histology, specifically, zone 3 sinusoidal fibrosis plus periportal fibrosis (stage 2), advanced fibrosis [bridging fibrosis (stage 3) or cirrhosis (stage 4)] [2, 45], associated with the multiple component of MetS [46]. Patients with stage 4 fibrosis (cirrhosis) had a nearly tenfold risk of liverrelated complications [2], with liver-related events occurring in 8.9 per 100 person-years (95\% CI 6.7-11.7). The reported annual incidence of hepatic decompensation was 3.3 and 15.6 per 100 person-years among patients with Child Pugh (CP)-A5 and CP-A6 cirrhosis, respectively [47].

\section{Hepatocellular carcinoma and extrahepatic cancers}

NAFLD is the third-most common cause of HCC in the United States, after hepatitis $\mathrm{C}$ and alcohol-related disease, accounting for $14.1 \%$ of all cases [48]. The cumulative incidence of NAFLD-associated HCC has been reported to range from 2.4 to $12.8 \%$ over a median follow-up period of 3.2-7.2 years [49], corresponding to 0.44 (range $0.29-0.66$ ) per 1000 person-years and increasing at a $9 \%$ annual rate $[1,48,50]$. Patients with NAFLD fibrosis stages F3 and F4 have an almost sevenfold increased risk of HCC compared to people without liver disease [48] and the risk is $>10$-fold higher in association with T2DM and obesity [51], making NAFLD the second leading cause of liver transplantation (LT) due to HCC in US and the most rapidly increasing indication [52]. At diagnosis, patients with NAFLD-related HCC are older, have higher prevalence of extrahepatic comorbidities but lower prevalence of cirrhosis (absence of cirrhosis in up to 1/3 of cases), and shorter survival time [49], being more likely to die from their primary liver cancer than other HCC patients [48]. These conditions may be driven by less systematic surveillance, leading to diagnosis at later stage and less treatment [53].

Other extra-hepatic cancers are similarly increased, namely cancers of the uterus (IRR $2.3 ; 95 \%$ CI 1.4, 4.1), stomach (IRR 2.3; 95\% CI 1.3, 4.1), pancreas (IRR 2.0; 95\% CI 1.2, 3.3) and colon (IRR 1.8; 95\% CI 1.1, 2.8) [53]. The association with cancer risk is stronger in NAFLD than in obesity [54].

\section{Lean NAFLD}

The term 'lean' NAFLD refers to patients with a BMI within the ethnic-specific cut-off of normal weight, but frequently extended to the area of overweight $\left(30 \mathrm{~kg} / \mathrm{m}^{2}\right.$ in Caucasian and $27 \mathrm{~kg} / \mathrm{m}^{2}$ in Asian subjects). It is conceivable that 'lean' NAFLD comprises an heterogeneous NAFLD cohort associated with environmental and genetic factors, as well as differences in fat distribution and body composition [55], accounting for $5-26 \%$ of total NAFLD cases in the Asian population and $7-20 \%$ in the Western areas [55]. A recent meta-analysis of 33 observational studies from 14 countries concluded for a global prevalence of NAFLD in lean individuals $\left(\mathrm{BMI}<23 \mathrm{~kg} / \mathrm{m}^{2}\right.$ for Asian subjects and BMI $<25 \mathrm{~kg} / \mathrm{m}^{2}$ for non-Asian subjects) of $9.7 \%$ (95\% CI 7.7-11.8\%), with an upward trend between 1988 and 2017 [56]. Their rate of comorbidity is lower compared to obese patients, but higher compared to healthy controls $[57,58]$. Data on histological severity are controversial; they can develop the full spectrum of liver disease associated with NASH [59] and similar adverse health outcomes when longitudinally examined [60, 61].

\section{Methods for guideline development}

Following the needs of an updated guidance upon clinical management of the Non Alcoholic Fatty Liver Disease, the Scientific Societies whose members are primarily involved in its management (Italian Association for the Study of the Liver-AISF; Italian Society of Diabetology-SID; Italian Society of Obesity-SIO) commissioned to an experts panel the drafting of a new dedicated document to outline the updated clinical practice guidelines. The present document was made according to the rules dictated by the Italian Center for the Cure Excellence (Centro Nazionale per l'Eccellenza delle Cure-CNEC), an institution recently set up by the Italian National Institute of Health (Istituto Superiore di Sanità-ISS) to outline the methodologies needed to provide evidence-based clinical, diagnostic and therapeutic guidelines in Italy [62]. According to these rules, a "multi-societary" and "multi-disciplinary" committee of experts was selected by the abovementioned Scientific Societies. The committee defined the objectives, the key issues and retrieved the relevant evidences by performing a systematic review of literature. Finally, the committee members (chosen on the basis of their specific expertise) identified the guidelines' key questions and developed them following the PICO format (Population, Intervention, Comparison, Outcomes) [63]. The most relevant questions were chosen by voting among the whole committee. The mean agreement among panel members on recommendations was $98.15 \%$, as reported in supplementary table 1 . For each PICO question, a systematic review of the literature was made on the most important scientific databases (Pubmed, Scopus, Embase) by performing both a free-text research and by a BOOLEAN research string formulated on purpose (see Online Appendix 1). The profiles of evidence were developed by applying the GRADE-Evidence to Decision (EtD) frameworks as per CNEC manual indications [62, 64]. In particular, all aspects regarding the questions, the assessment of evidence and the conclusions drawings were discussed between the panel members and voted to obtain a final decision. The GRADEpro GDT online tool was used to develop the questions and make the decisions 
[65]. The quality of evidence was evaluated by applying the "Quality Assessment of Diagnostic Accuracy Studies version 2" (QUADAS-2) checklist for the diagnostic accuracy questions [66], the "revised tool for Risk of Bias in randomized trials" (RoB 2) [67] and the "Risk Of Bias in Non-randomized Studies - of Interventions" tool (ROBINS-I) [68] for randomized clinical trials and non-randomized studies where applicable.

The final draft was submitted for advice and revision to EpaC (Liver Patients' Association). Their comments were considered in the final version.

\section{Strength and limits}

The present report is a summary of Clinical Practice Guidelines resulting from a cooperative multi-society work and by using rigorous methodology suggested in Italy by the Centro Nazionale per l'Eccellenza delle cure and Istituto Superiore di Sanità. Lack of awareness for NAFLD and obstacles to apply and implement guidelines could limit their utility.

\section{What is already known on this subject?}

NAFLD is an emerging liver disease with a growing epidemiological and clinical burden.

National guidelines for the management of NAFLD patients are not still available.

\section{What this study adds?}

The present document is the first effort to provide multisociety national guidelines on NAFLD aimed to a multidisciplinary and shared management of NAFLD patients.

\section{PICO Questions and recommendations}

\section{(A) Assessment of disease severity}

\section{PICO 1-In adult patients with NAFLD, should non-invasive scores, serum markers, liver stiffness, and imaging methods be used as replacement for liver biopsy for the diagnosis of NASH?}

\section{Recommendation}

- In patients with NAFLD non-invasive tests do not have acceptable accuracy for the diagnosis of NASH, and liver biopsy remains the reference standard $(\mathrm{B}, 2)$
References: [4, 69-74].

\section{PICO 2-In adult patients with NAFLD, should non-invasive scores, serum markers, liver stiffness and imaging methods be used as replacement for liver biopsy for the diagnosis of advanced fibrosis?}

\section{Recommendation}

- In patients with NAFLD, simple noninvasive scores, namely the Fibrosis-4 score (FIB-4) and the NAFLD fibrosis score (NFS), as well as liver stiffness measurement (LSM), using transient elastography, have acceptable accuracy to identify NAFLD cases at low risk of advanced fibrosis $(\mathrm{A}, 1)$

- A two-tier sequential combination of simple noninvasive scores like FIB-4 or NFS with imaging techniques such as LSM by transient elastography is recommended as a triage test for ruling out advanced fibrosis sparing further testing $(\mathrm{B}, 2)$

- Magnetic resonance elastography (MRE) is the most accurate noninvasive method for estimation of liver fibrosis. This technique can be preferred in clinical trials, but it is not recommended in clinical practice, being expensive and very rarely available $(\mathrm{B}, 2)$

References: [75-101].

Figure 1 depicts a two-step algorithm, based on FIB-4 or NAFLD fibrosis score as first step followed by LSM,

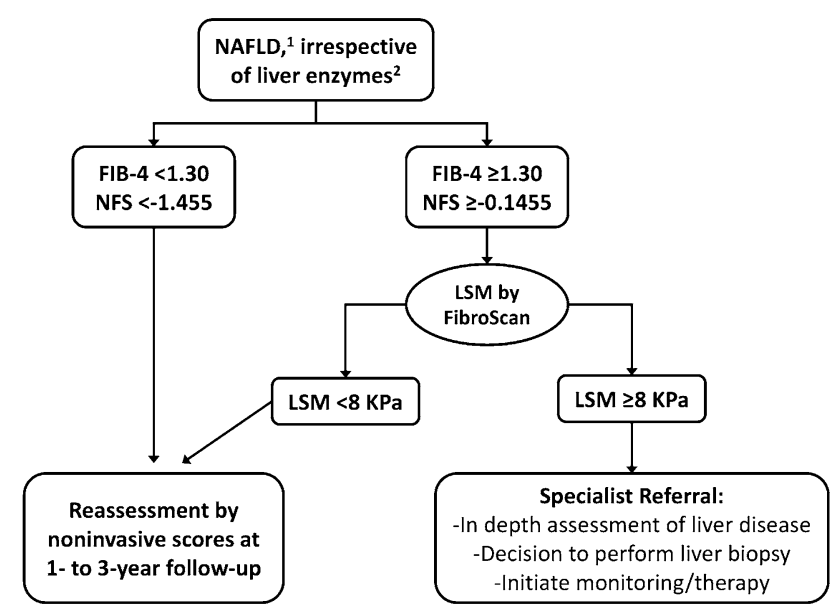

Fig. $1{ }^{1}$ NAFLD is defined by ultrasound; in case of difficult access to ultrasound, clinicians can directly screen patients with features of metabolic syndrome by liver enzymes and noninvasive scores of fibrosis: ${ }^{2}$ AST, ALT, GGT. Note that in patients referred to specialists (right side) follow-up will depend on disease severity/available therapeutic protocols; timing of follow-up in negative patients (left side) will depend on the presence of metabolic factors and comorbid conditions 
proposed for the assessment of fibrosis severity in patients with NAFLD.

\section{PICO 3-In adult patients with NAFLD, should non-invasive scores, liver stiffness and imaging methods be used as replacement for liver biopsy for predicting liver-related outcomes?}

\section{Recommendations}

- In patients with NAFLD, non-invasive tools might acceptably rule out fibrosis progression $(\mathrm{C}, 2)$

- In patients with NAFLD, noninvasive tools might acceptably predict the risk of occurrence of overall and liverrelated events and mortality $(\mathrm{C}, 2)$

References: [35, 102-112].

PICO 4-In adult patients with NAFLD, should genetic testing be used as an add-on after usual testing in predicting the severity of histologically assessed liver damage and liver-related outcomes?

\section{Recommendations}

- Clinicians in referral centers might consider the genetic risk profile for stratification of individual NAFLD-HCC risk, but the effectiveness of such strategy requires larger prospective studies $(\mathrm{C}, 2)$

- We suggest that genetic risk variants be evaluated in clinical studies for stratification of disease risk progression and sub-phenotyping of NAFLD ( $\underline{\mathrm{B}}, 2)$

References: [3, 4, 113-123].

Supplementary Table 2.

(B) Weight loss and behavioral intervention for NAFLD

\section{PICO 5-In adult patients with NAFLD, what} is the efficacy of weight loss on histologically assessed liver damage and liver-related outcomes in comparison with no intervention?

\section{Recommendation}

- All subjects with NAFLD, including lean (non-obese) NAFLD, should be involved in lifestyle programs aimed at healthy diet and habitual physical activity to $a \geq 7-10 \%$ weight loss target, repeatedly associated with improved histology, including fibrosis $(\mathrm{B}, 1)$
- The dietary approach to NAFLD should favor adherence to the principles of the Mediterranean diet, including a reduced intake of refined and industrial sugars, associated with reduced hepatic fat content and decreased cardiovascular risk $(\mathrm{B}, 1)$

- Low-modest alcohol intake in noncirrhotic NAFLD patients should not be encouraged $(\mathrm{C}, 2)$ and total abstinence in NAFLD-cirrhosis is recommended $(\mathrm{B}, 1)$

- In patients with NAFLD, any types of physical activity, as well as reduced sedentariness, should be counseled, in order to reduce liver fat, independently of changes in body weight $(\mathrm{B}, 1)$

- Clinicians should recommend weight loss by intensive, structured lifestyle programs delivered under specialist control and/or pharmacotherapy and/or bariatric surgery in NAFLD subjects with obesity to reduce liver disease severity $(\mathrm{A}, 1)$

References: [9, 124-175].

(C) Pharmacologic treatment for NAFLD

The epidemic of NAFLD and its complications and the discovery of different potential therapeutic targets for NASH treatment led to start an impressive number of clinical trials. International guidelines recommend that pharmacological therapy for NAFLD/NASH should be reserved to patients presenting an active disease and the presence of liver fibrosis $\geq$ stage $2[176,177]$. Moreover, the FDA (US Food and Drug Administration) and the EMA (European Medicines Agency) identified two endpoints for the conditional approval of drugs in patients with noncirrhotic NASH: (1) resolution of NASH without worsening of liver fibrosis, and (2) at least one stage improvement in liver fibrosis without worsening of NASH fibrosis [177]. Consistently, most of the phase $2 b$ and phase 3 trials enrolled patients with NASH plus fibrosis stage F2-F3. However, in spite of a large number of published or ongoing clinical trials, to date neither FDA, nor EMA or AIFA has approved any pharmacological treatment for patients with NASH.

PICO 6-In adult patients with NAFLD, what is the efficacy of pharmacological treatment on histologically assessed liver damage and liver-related outcomes in comparison with no pharmacological intervention?

\section{Recommendation}

- In patients with NASH pioglitazone may be used to improve NASH and fibrosis, although the drug is off- 
label and the risk/benefit balance related to pioglitazone side-effects should be discussed with each patient $(\mathrm{B}, 2)$

- In patients with NASH vitamin E may be used to improve NASH and fibrosis, even if risks and benefits should be discussed with each patient $(\mathrm{B}, 2)$

- In patients with NASH standard or high-dose ursodeoxycholic acid (UDCA) should not be used to treat NASH and fibrosis, because ineffective $(\mathrm{B}, 2)$

- In patients with NASH obeticholic acid may improve fibrosis without worsening of NASH, but its use is waiting for approval by regulatory agencies, based on additional safety and efficacy data $(\mathrm{B}, 2)$

References for pioglitazone: [178-193].

References for vitamin E: [181, 194-201].

References for ursodeoxycholic acid: [202-205].

References for obeticholic acid: [206-208].

PICO 7-In adult patients with NAFLD and type

2 diabetes mellitus, what is the efficacy

of glucose-lowering treatment on histologically assessed liver damage and liver-related outcomes?

\section{Recommendation}

- In T2DM patients with NAFLD/NASH, pioglitazone is specifically recommended to treat liver disease $(\mathrm{B}, 2)$

- In T2DM patients with NAFLD/NASH, metformin use is safe for the liver, but it is not specifically recommended to treat liver disease $(\mathrm{B}, 2)$

- In T2DM patients with NAFLD/NASH, DPP-4 inhibitors are safe for the liver, but their use is not specifically recommended to treat liver disease $(\mathrm{C}, 2)$

- In T2DM patients with NAFLD/NASH, GLP-1 receptor agonists are safe for the liver, but, despite preliminary evidence that may decrease liver damage, their use is not specifically approved to treat liver disease $(\mathrm{B}, 2)$

- In T2DM patients with NAFLD/NASH, SGLT-2 inhibitors are safe for the liver, but their use is not specifically recommended to treat liver disease $(\mathrm{C}, 2)$

References for metformin: [184, 209-214].

References for DPP-4 inhibitors: [215-219].

References for GLP-1 receptor agonists: [140, 218, 220-227].

References for SGLT-2 inhibitors: [228-238].

(D) NAFLD and liver transplantation
PICO 8-In adult patients with NASH candidate

for liver transplantation, should the evaluation of cardiometabolic comorbidities in the preand post-transplant phase be different from that of patients with liver disease of other etiology in order to reduce cardiovascular complications?

\section{Recommendation}

- In liver transplant candidates with NASH-related decompensated cirrhosis or NASH-HCC, both at particularly high risk of developing cardiovascular events, cardiovascular risk factors should be assessed by a multidisciplinary team, which includes a transplant cardiologist and a transplant anesthesiologist, but no universally validated algorithms are available for a comprehensive evaluation $(\mathrm{C}, 1)$

- Thorough screening for hypertension, diabetes, and dyslipidemia is recommended in patients with NASH undergoing evaluation for liver transplantation and appropriate medical treatment in wait-listed patients is mandatory to reduce events and de-listing $(\mathrm{B}, 1)$

- Obesity alone does not constitute a contraindication for liver transplantation. Patients with decompensated $\mathrm{NASH}$-cirrhosis or NASH-HCC and morbid obesity (body mass index $>40 \mathrm{~kg} / \mathrm{m}^{2}$ should be listed on a highly individualized basis, especially in the presence of diabetes $(\mathrm{B}, 2)$

References: [36, 53, 239-253].

\section{PICO 9-In adult patients with NASH and morbid obesity, candidate for liver transplantation, what is the efficacy of bariatric surgery on pre- and post-transplant outcomes in comparison with no bariatric surgery?}

\section{Recommendation}

- Bariatric surgery may improve outcomes in patients with morbid obesity in the setting of liver transplantation; however, in decompensated cirrhosis it is associated with higher risk of morbidity and mortality; too few data are available to recommend the procedure before, during or after transplantation $(\mathrm{C}, 2)$

References: [254-262]. 
(E) NAFLD ascertainment in the general population

\section{PICO 10 - In the adult population are non-invasive scores and imaging methods useful for the diagnosis of NAFLD?}

\section{Recommendations}

- Non-invasive scores (Fatty Liver Index-FLI) may be useful in population studies for the diagnosis of steatosis (A, 1)

- Ultrasonography (US) is the first-line diagnostic procedure for detecting NAFLD, as it has high accuracy for moderate-severe steatosis and also provides additional diagnostic information $(\mathrm{A}, 1)$

- ${ }^{1} \mathrm{H}$-Magnetic Resonance Spectroscopy (MRS) is the reference standard for a quantitative estimation of liver fat. This technique should be preferred in clinical trials, but it is not recommended in clinical practice because expensive and not largely available (A, 2)

- Controlled Attenuation Parameter (CAP) is an alternative tool for non-invasive assessment and follow-up of steatosis but more data are needed to definitively define its role (B, 2)

References: [263-275].

\section{PICO 11-In adult population with metabolic risk factors are non-invasive scores, liver stiffness and imaging methods useful for the diagnosis of advanced fibrosis?}

\section{Recommendations}

- In adult individuals with one or more features of the metabolic syndrome, a combination of non-invasive fibrosis markers may help improve referral of patients with advanced liver fibrosis from primary care to specialist setting, also reducing the cost of management $(\mathrm{B}, 2)$

References: [16, 47, 276-282].

\section{Conclusion}

In the past few years, NAFLD emerged as a common liver disease in adults frequently associated with metabolic alterations, and as a leading cause of HCC and liver decompensation, finally impacting resource utilization and costs of the Healthcare systems. Also in Italy, the cost associated with NAFLD for the National Health System is rapidly increasing [28]. The growing interest for NAFLD lead to the development of new diagnostic tools and algorithms to identify and refer patients at high risk of liver damage to liver specialists for assessment and treatment. The implementation of lifestyle programs aimed at weight loss and ongoing clinical trials with drugs targeting pathogenic pathways responsible for necroinflammation and fibrosis open new scenario in the management of NAFLD patients [283].

The present guidelines are conceived to promote a fruitful collaboration between different specialties, in a multidisciplinary approach aimed at disseminating and improving treatment within the healthcare professionals. Given the impressive amount of research and the extraordinary advances of the past few years, the several attempts to define new treatment strategies and the large number of trials supported by pharmaceutical companies, the proposed recommendations should be considered provisional and the Writing Commission recommends systematic update of Guidelines at regular intervals.

Finally, given its epidemiological, clinical and economic burden, NAFLD should be classified as a definite liver disease by the Health Care Italian System, independently of the presence of other metabolic comorbidities, with appropriate regulations in terms of diagnosis and treatment.

\section{Appendix 1: Bibliographic research strategy}

- identification of information needs: scientific evidence concerning the pathogenesis, diagnosis and treatment of non-alcoholic steatosis.

- planning of the research strategy: for each topic assigned, the researchers personally searched for the bibliographic sources, using digital or paper resources if necessary.

- choice of tools for information retrieval: the identified articles were obtained from the online library of the Institution to which the member of the experts' panel belongs. If not available online, the article was searched among the paper volumes of institutional libraries or was obtained through a direct request to the author of the publication.

- identification of adequate sources of information: only articles from journals indexed on scientific search engines (PubMed, Embase, Scopus) were included, excluding non-scientific repertoires and newspapers articles, case reports, conference abstracts not published in-extenso. The keywords used for the research were the following:

1 Research topic: classification, diagnosis and prognosis of non-alcoholic steatosis. 
Free-text research keywords: liver steatosis, nonalcoholic fatty liver, non-alcoholic fatty liver disease, non-alcoholic steatohepatitis, classification, diagnosis, prognosis.

BOOLEAN research string:

(("Non-alcoholic Fatty Liver Disease"[Mesh] OR non alcoholic fatty liver disease*[Title/Abstract] OR non-alcoholic fatty liver disease*[Title/Abstract] OR nonalcoholic fatty liver disease*[Title/Abstract] OR nonalcoholic fatty liver*[Title/Abstract] OR non alcoholic steatohepatitis*[Title/Abstract])) AND ("Liver Diseases"[Mesh])

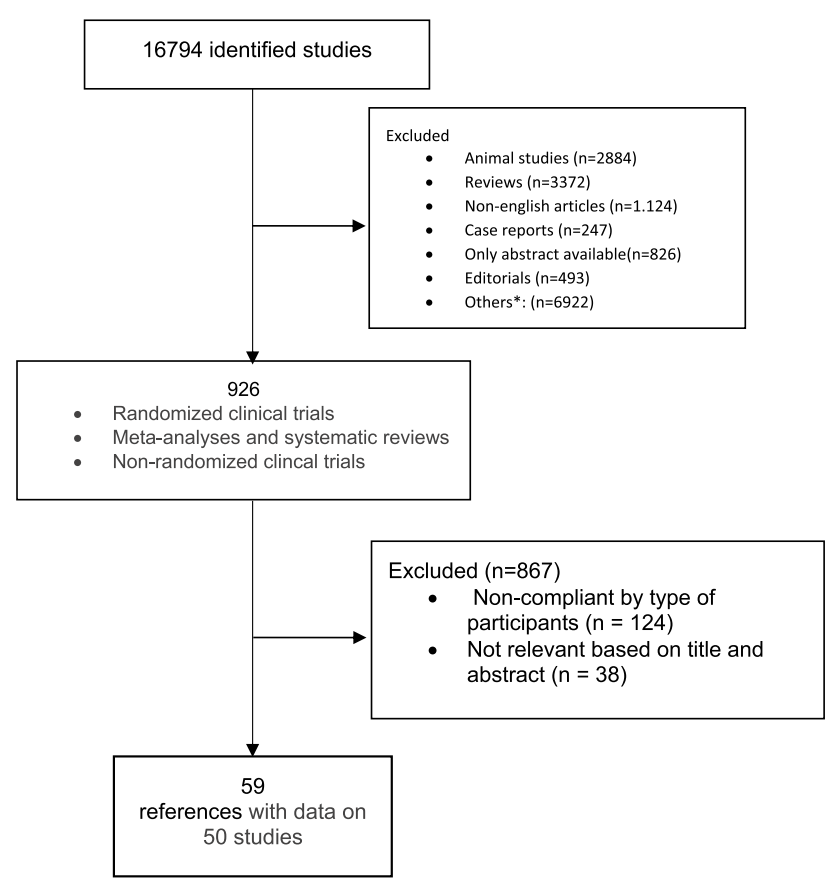

2. Research topic: non-invasive diagnosis of NAFLD

Free-text research keywords: non- alcoholic fatty liver disease, therapy, liver disease:

BOOLEAN research string:

(("Non-alcoholic Fatty Liver Disease"[Mesh] OR non alcoholic fatty liver disease*[Title/Abstract] OR non-alcoholic fatty liver disease*[Title/Abstract] OR nonalcoholic fatty liver disease*[Title/Abstract] OR nonalcoholic fatty liver*[Title/Abstract] OR non alcoholic steatohepatitis*[Title/Abstract])) AND (("Liver Cirrhosis"[Mesh] OR liver fibrosis*[Title/ Abstract] OR hepatic fibrosis*[Title/Abstract] OR cirrhosis*[Title/Abstract] OR cirrhoses*[Title/ Abstract])) AND ((16 APRI*[Title/Abstract] OR aspartate aminotransferase to platelets ratio index*[Title/Abstract]) OR (FIB-4*[Title/Abstract] OR fibrosis-4 index*[Title/Abstract]) OR (NAFLD fibrosis score*[Title/Abstract] OR NFS*[Title/
Abstract]) OR (BARD score*[Title/Abstract]) OR ("Elasticity Imaging Techniques"[Mesh] OR Elasticity Imaging Techniques[Title/ Abstract]) OR (elastography*[Title/Abstract] OR elastograph*[Title/Abstract]) OR (FibroScan*[Title/ Abstract] OR transient elastography*[Title/ Abstract]) OR (shear wave elastography*[Title/ Abstract]) OR (magnetic resonance elastography*[Title/Abstract] OR (38 MRE[Title/ Abstract])).

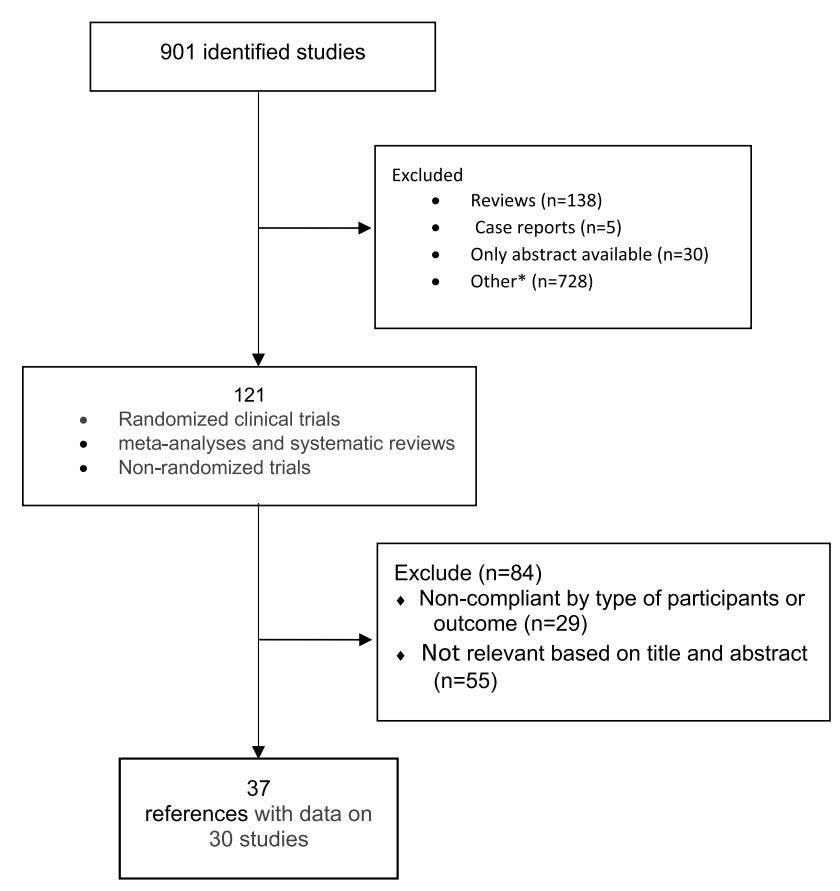

3. Research topic: NAFLD therapy

Free-text reseach keywords: Non alcoholic fatty liver disease, therapy, liver disease

BOOLEAN research string:

(("Non-alcoholic Fatty Liver Disease"[Mesh] OR non alcoholic fatty liver disease*[Title/Abstract] OR non-alcoholic fatty liver disease*[Title/Abstract] OR nonalcoholic fatty liver disease*[Title/Abstract] OR nonalcoholic fatty liver*[Title/Abstract] OR non alcoholic steatohepatitis*[Title/Abstract])) AND (("Therapy"[MeSH] OR "Pharmacological therapy" [MeSH] OR Drug*[Title/Abstract] OR Therap*[Title/Abstract]) OR (exercise[Title/ Abstract] OR resistance training[Title/Abstract] OR aerobic training[Title/Abstract] OR aerobic exercise[Title/Abstract] OR circuit training[Title/ Abstract] OR walk test[Title/Abstract] OR endurance training[Title/Abstract] OR strength 
training[Title/Abstract] OR weight training[Title/ Abstract]))

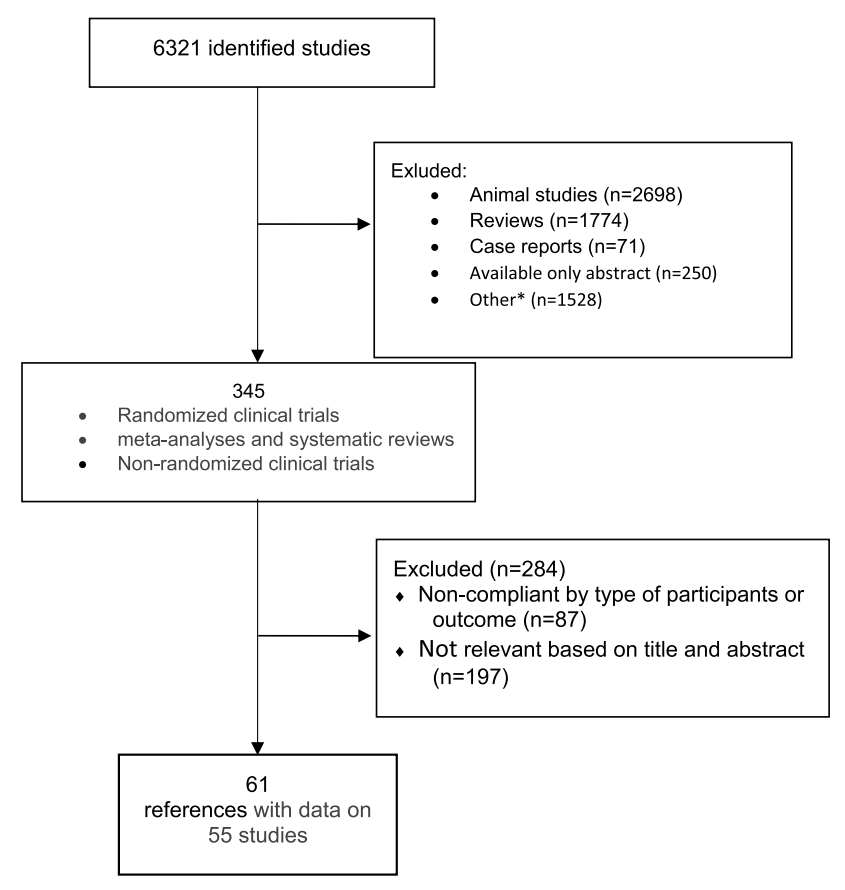

\section{Appendix 2. Members of the guidelines panel}

Coordinator: Giulio Marchesini; AISF Members: Elisabetta Bugianesi, Patrizia Burra, Fabio Marra, Luca Miele, Anna Alisi, Piero Vajro, Mario Masarone, Salvatore Petta, Marcello Persico, Gianluca Svegliati-Baroni, Luca Valenti; SID Members: Massimo Federici, Francesco Purrello, Ferdinando Carlo Sasso, Giovanni Targher; SIO Members: Luca Busetto, Maria Letizia Petroni, Ferruccio Santini; Metodologists: Calogero Cammà, Agostino Colli.

Supplementary Information The online version contains supplementary material available at https://doi.org/10.1007/s40519-021-01287-1.

Acknowledgements The Italian Association for the Study of Liver disease is indebted to Ivan Gardini and EpaC Onlus (Liver Patients' Association) for advice and revision of the manuscript. Their suggestions have been considered in the final version.

Funding Open access funding provided by Università degli Studi di Palermo within the CRUI-CARE Agreement.

\section{Declarations}

Conflict of interest Giulio Marchesini participated in NAFLD advisory boards of Astra-Zeneca, Pfizer, Gilead, Novartis and received honoraria for conference from Eli Lilly. Elisabetta Bugianesi: Consultant for Gilead, BMS, Boeringher, Intercept, Innova, Novo Nordisk. Patrizia Burra received personal fees from Biotest, Kedrion and Chiesi Farmaceutici for occasional scientific collaboration. Fabio Marra: Abbvie: consultant fees; Allergan: consultant fees; AstraZeneca: consultant fees; Gilead: speaker honoraria, consultant fees; Intercept: speaker honoraria; Menarini: consultant fees; Novartis: consultant fees; Novo Nordisk: consultant fees. Luca Miele: Advisory Board, Consultancy, Invited Speaker: Alfa-Sigma, Boehringer-Ingelheim, BMS, Echosens, Galmed, Gilead Sciences, IBSA, Intercept, MEDA, MyGenomics, Merck Sharp \& Dohme, Novartis, Pfizer, ProLon, Promethera, Rottapharm-Madaus, Siemens Healthineers, Synageva. Anna Alisi: no disclosures. Piero Vajro: no disclosures. Mario Masarone: Gilead travel grants, invited speech; Abbvie: travel grants, invited speech, advisory boards. Salvatore Petta: Advisor and/or Speaker for Abbvie, Gilead, Intercept and Pfyzer. Marcello Persico acted as consultant for Abbvie and Gilead. Gianluca Svegliati-Baroni: no disclosures. Luca Valenti: Speaking: MSD, Gilead, AlfaSigma, AbbVie; Consulting: Gilead, Pfizer, Astra Zeneca, Novo Nordisk, Intercept pharmaceuticals, Diatech Pharmacogenetics, IONIS; Research: Gilead. Massimo Federici: no disclosures. Francesco Purrello: no disclosures. Ferdinando Carlo Sasso has been member of Advisory Boards for Boehringer and for Ely-Lilly and has received fees for scientific consultation and/or lectures by Jansen, Roche Diagnostics, Novo Nordisk, Sanofi, MSD, Astrazeneca. Giovanni Targher: no disclosures. Luca Busetto: no disclosures. Maria Letizia Petroni: no disclosures. Ferruccio Santini has worked as a consultant, participated in studies, and/or received travel funds from the following companies, which are involved with obesity and related diseases: AstraZeneca, Aegerion Pharmaceuticals, Amryt, BioItalia, Bruno farmaceutici and Novo Nordisk. Calogero Cammà: no disclosures. Agostino Colli: no disclosures.

Ethical approval The article does not contain any studies with human participant or animals performed by any of the authors.

Informed consent For this type of study formal consent is not required.

Open Access This article is licensed under a Creative Commons Attribution-NonCommercial-NoDerivatives 4.0 International License, which permits any non-commercial use, sharing, distribution and reproduction in any medium or format, as long as you give appropriate credit to the original author(s) and the source, and provide a link to the Creative Commons licence. You do not have permission under this licence to share adapted material derived from this article or parts of it. The images or other third party material in this article are included in the article's Creative Commons licence, unless indicated otherwise in a credit line to the material. If material is not included in the article's Creative Commons licence and your intended use is not permitted by statutory regulation or exceeds the permitted use, you will need to obtain permission directly from the copyright holder. To view a copy of this licence, visit http://creativecommons.org/licenses/by-nc-nd/4.0/.

\section{References}

1. Younossi ZM, Koenig AB, Abdelatif D, Fazel Y, Henry L, Wymer M (2016) Global epidemiology of nonalcoholic fatty liver disease-Meta-analytic assessment of prevalence, incidence, and outcomes. Hepatology 64:73-84 
2. Sanyal AJ, Harrison SA, Ratziu V et al (2019) The natural history of advanced fibrosis due to nonalcoholic steatohepatitis: data from the simtuzumab trials. Hepatology 70:1913-1927

3. Dongiovanni P, Stender S, Pietrelli A et al (2018) Causal relationship of hepatic fat with liver damage and insulin resistance in nonalcoholic fatty liver. J Intern Med 283:356-370

4. European Association for the Study of the Liver, European Association for the Study of Diabetes, European Association for the Study of Obesity. EASL-EASD-EASO Clinical Practice Guidelines for the management of non-alcoholic fatty liver disease. J Hepatol 2016;64:1388-1402.

5. Eslam M, Newsome PN, Sarin SK et al (2020) A new definition for metabolic dysfunction-associated fatty liver disease: an international expert consensus statement. J Hepatol 73:202-209

6. Bedogni G, Miglioli L, Masutti F, Tiribelli C, Marchesini G, Bellentani S (2005) Prevalence of and risk factors for nonalcoholic fatty liver disease: the Dionysos nutrition and liver study. Hepatology 42:44-52

7. Pendino GM, Mariano A, Surace P et al (2005) Prevalence and etiology of altered liver tests: a population-based survey in a Mediterranean town. Hepatology 41:1151-1159

8. Caserta CA, Mele A, Surace P et al (2017) Association of nonalcoholic fatty liver disease and cardiometabolic risk factors with early atherosclerosis in an adult population in Southern Italy. Ann Ist Super Sanita 53:77-81

9. Petta S, Di Marco V, Pipitone RM et al (2018) Prevalence and severity of nonalcoholic fatty liver disease by transient elastography: genetic and metabolic risk factors in a general population. Liver Int 38:2060-2068

10. Alberti KG, Eckel RH, Grundy SM et al (2009) Harmonizing the metabolic syndrome: a joint interim statement of the International Diabetes Federation Task Force on Epidemiology and Prevention; National Heart, Lung, and Blood Institute; American Heart Association; World Heart Federation; International Atherosclerosis Society; and International Association for the Study of Obesity. Circulation 120:1640-1645

11. Colicchio P, Tarantino G, del Genio F et al (2005) Non-alcoholic fatty liver disease in young adult severely obese nondiabetic patients in South Italy. Ann Nutr Metab 49:289-295

12. Soresi M, Noto D, Cefalu AB et al (2013) Nonalcoholic fatty liver and metabolic syndrome in Italy: results from a multicentric study of the Italian Arteriosclerosis society. Acta Diabetol 50:241-249

13. Bellentani S, Saccoccio G, Masutti F et al (2000) Prevalence of and risk factors for hepatic steatosis in Northern Italy. Ann Intern Med 132:112-117

14. Marchesini G, Avagnina S, Barantani EG et al (2005) Aminotransferase and gamma-glutamyltranspeptidase levels in obesity are associated with insulin resistance and the metabolic syndrome. J Endocrinol Investig 28:333-339

15. Non-alcoholic Fatty Liver Disease Study Group, Lonardo A, Bellentani S et al (2015) Epidemiological modifiers of nonalcoholic fatty liver disease: focus on high-risk groups. Dig Liver Dis 47:997-1006

16. Younossi ZM, Golabi P, de Avila L et al (2019) The global epidemiology of NAFLD and NASH in patients with type 2 diabetes: a systematic review and meta-analysis. J Hepatol 71:793-801

17. Targher G, Lonardo A, Byrne CD (2018) Nonalcoholic fatty liver disease and chronic vascular complications of diabetes mellitus. Nat Rev Endocrinol 14:99-114

18. Anstee QM, Targher G, Day CP (2013) Progression of NAFLD to diabetes mellitus, cardiovascular disease or cirrhosis. Nat Rev Gastroenterol Hepatol 10:330-344
19. Forlani G, Giorda C, Manti R et al (2016) The burden of NAFLD and its characteristics in a nationwide population with type 2 diabetes. J Diabetes Res 2016:2931985

20. Targher G, Mantovani A, Pichiri I et al (2013) Non-alcoholic fatty liver disease is associated with an increased prevalence of atrial fibrillation in hospitalized patients with type 2 diabetes. Clin Sci (Lond) 125:301-309

21. Giorda CB, Forlani G, Manti R et al (2018) Trend over time in hepatic fibrosis score in a cohort of type 2 diabetes patients. Diabetes Res Clin Pract 135:65-72

22. Targher G, Marchesini G, Byrne CD (2016) Risk of type 2 diabetes in patients with non-alcoholic fatty liver disease: causal association or epiphenomenon? Diabetes Metab 42:142-156

23. Porepa L, Ray JG, Sanchez-Romeu P, Booth GL (2010) Newly diagnosed diabetes mellitus as a risk factor for serious liver disease. CMAJ 182:E526-531

24. Wild SH, Morling JR, McAllister DA et al (2016) Type 2 diabetes and risk of hospital admission or death for chronic liver diseases. J Hepatol 64:1358-1364

25. Zoppini G, Fedeli U, Gennaro N, Saugo M, Targher G, Bonora E (2014) Mortality from chronic liver diseases in diabetes. Am J Gastroenterol 109:1020-1025

26. Sun DQ, Ye FZ, Kani HT et al (2020) Higher liver stiffness scores are associated with early kidney dysfunction in patients with histologically proven non-cirrhotic NAFLD. Diabetes Metab 46:288-295

27. Younossi ZM, Tampi R, Priyadarshini M, Nader F, Younossi IM, Racila A (2019) Burden of illness and economic model for patients with nonalcoholic steatohepatitis in the United States. Hepatology 69:564-572

28. Petta S, Ting J, Saragoni S et al (2020) Healthcare resource utilization and costs of nonalcoholic steatohepatitis patients with advanced liver disease in Italy. Nutr Metab Cardiovasc Dis 30:1014-1022

29. Adams LA, Lymp JF, St Sauver J et al (2005) The natural history of nonalcoholic fatty liver disease: a population-based cohort study. Gastroenterology 129:113-121

30. Younossi Z, Henry L (2016) Contribution of alcoholic and nonalcoholic fatty liver disease to the burden of liver-related morbidity and mortality. Gastroenterology 150:1778-1785

31. Spahillari A, Mukamal KJ, DeFilippi C et al (2016) The association of lean and fat mass with all-cause mortality in older adults: the Cardiovascular Health Study. Nutr Metab Cardiovasc Dis 26:1039-1047

32. Stepanova M, Younossi ZM (2012) Independent association between nonalcoholic fatty liver disease and cardiovascular disease in the US population. Clin Gastroenterol Hepatol 10:646-650

33. Bhatia LS, Curzen NP, Calder PC, Byrne CD (2012) Non-alcoholic fatty liver disease: a new and important cardiovascular risk factor? Eur Heart J 33:1190-1200

34. Lonardo A, Nascimbeni F, Mantovani A, Targher G (2018) Hypertension, diabetes, atherosclerosis and NASH: cause or consequence? J Hepatol 68:335-352

35. Kim D, Kim WR, Kim HJ, Therneau TM (2013) Association between noninvasive fibrosis markers and mortality among adults with nonalcoholic fatty liver disease in the United States. Hepatology 57:1357-1365

36. Targher G, Byrne CD, Lonardo A, Zoppini G, Barbui C (2016) Non-alcoholic fatty liver disease and risk of incident cardiovascular disease: a meta-analysis. J Hepatol 65:589-600

37. Ekstedt M, Hagstrom H, Nasr P et al (2015) Fibrosis stage is the strongest predictor for disease-specific mortality in NAFLD after up to 33 years of follow-up. Hepatology 61:1547-1554

38. Ballestri S, Zona S, Targher G et al (2016) Nonalcoholic fatty liver disease is associated with an almost twofold increased 
risk of incident type 2 diabetes and metabolic syndrome. Evidence from a systematic review and meta-analysis. J Gastroenterol Hepatol 31:936-944

39. Sung KC, Wild SH, Byrne CD (2013) Resolution of fatty liver and risk of incident diabetes. J Clin Endocrinol Metab 98:3637-3643

40. Yamazaki H, Tsuboya T, Tsuji K, Dohke M, Maguchi H (2015) Independent association between improvement of nonalcoholic fatty liver disease and reduced incidence of type 2 diabetes. Diabetes Care 38:1673-1679

41. Mantovani A, Zaza G, Byrne CD et al (2018) Nonalcoholic fatty liver disease increases risk of incident chronic kidney disease: a systematic review and meta-analysis. Metabolism 79:64-76

42. Byrne CD, Targher G (2015) NAFLD: a multisystem disease. J Hepatol 62:S47-64

43. Sayiner M, Koenig A, Henry L, Younossi ZM (2016) Epidemiology of nonalcoholic fatty liver disease and nonalcoholic steatohepatitis in the United States and the rest of the world. Clin Liver Dis 20:205-214

44. Global Burden of Disease 2015 Mortality and Causes of Death Collaborators (2016) Global, regional, and national life expectancy, all-cause mortality, and cause-specific mortality for 249 causes of death, 1980-2015: a systematic analysis for the Global Burden of Disease Study 2015. Lancet 388:1459-1544

45. Angulo P, Kleiner DE, Dam-Larsen S et al (2015) Liver fibrosis, but no other histologic features, is associated with long-term outcomes of patients with nonalcoholic fatty liver disease. Gastroenterology 149:389-397 (e310)

46. Younossi ZM (2019) Non-alcoholic fatty liver disease-a global public health perspective. J Hepatol 70:531-544

47. Vilar-Gomez E, Calzadilla-Bertot L, Wai-Sun Wong V et al (2018) Fibrosis severity as a determinant of cause-specific mortality in patients with advanced nonalcoholic fatty liver disease: a multi-national cohort study. Gastroenterology 155:443-457 (e417)

48. Younossi ZM, Otgonsuren M, Henry L et al (2015) Association of nonalcoholic fatty liver disease (NAFLD) with hepatocellular carcinoma (HCC) in the United States from 2004 to 2009. Hepatology 62:1723-1730

49. Younes R, Bugianesi E (2018) Should we undertake surveillance for HCC in patients with NAFLD? J Hepatol 68:326-334

50. Ioannou GN, Green P, Kerr KF, Berry K (2019) Models estimating risk of hepatocellular carcinoma in patients with alcohol or NAFLD-related cirrhosis for risk stratification. J Hepatol 71:523-533

51. Dyson J, Jaques B, Chattopadyhay D et al (2014) Hepatocellular cancer: the impact of obesity, type 2 diabetes and a multidisciplinary team. J Hepatol 60:110-117

52. Wong RJ, Cheung R, Ahmed A (2014) Nonalcoholic steatohepatitis is the most rapidly growing indication for liver transplantation in patients with hepatocellular carcinoma in the US. Hepatology 59:2188-2195

53. Piscaglia F, Svegliati-Baroni G, Barchetti A et al (2016) Clinical patterns of hepatocellular carcinoma in nonalcoholic fatty liver disease: a multicenter prospective study. Hepatology 63:827-838

54. Allen AM, Hicks SB, Mara KC, Larson JJ, Therneau TM (2019) The risk of incident extrahepatic cancers is higher in non-alcoholic fatty liver disease than obesity-a longitudinal cohort study. J Hepatol 71:1229-1236

55. Younes R, Bugianesi E (2019) NASH in lean individuals. Semin Liver Dis 39:86-95

56. Lu FB, Zheng KI, Rios RS, Targher G, Byrne CD, Zheng MH (2020) Global epidemiology of lean non-alcoholic fatty liver disease: a systematic review and meta-analysis. J Gastroenterol Hepatol 35:2041-2050
57. Feldman A, Eder SK, Felder TK et al (2017) Clinical and metabolic characterization of lean caucasian subjects with non-alcoholic fatty liver. Am J Gastroenterol 112:102-110

58. Younossi ZM, Otgonsuren M, Venkatesan C, Mishra A (2013) In patients with non-alcoholic fatty liver disease, metabolically abnormal individuals are at a higher risk for mortality while metabolically normal individuals are not. Metabolism 62:352-360

59. Fracanzani AL, Valenti L, Bugianesi E et al (2011) Risk of nonalcoholic steatohepatitis and fibrosis in patients with nonalcoholic fatty liver disease and low visceral adiposity. J Hepatol 54:1244-1249

60. Dela Cruz AC, Bugianesi E, George J et al (2014) Characteristics and long-term prognosis of lean patients with nonalcoholic fatty liver disease. Gastroenterology 146:S-909

61. Hagstrom H, Nasr P, Ekstedt M et al (2018) Risk for development of severe liver disease in lean patients with nonalcoholic fatty liver disease: a long-term follow-up study. Hepatol Commun 2:48-57

62. CNEC-Centro Nazionale per l'Eccellenza delle Cure (2020) Manuale metodologco per la Produzione di Linee Guida di Pratica Clinica. ISS-Istituto Superiore di Sanità, Roma. https:// snlg.iss.it/wp-content/uploads/2019/04/MM_v1.3.2_apr_2019. pdf

63. Guyatt GH, Oxman AD, Kunz R et al (2011) GRADE guidelines: 2. Framing the question and deciding on important outcomes. J Clin Epidemiol 64:395-400

64. Moberg J, Oxman AD, Rosenbaum S et al (2018) The GRADE Evidence to Decision (EtD) framework for health system and public health decisions. Health Res Policy Syst 16:45

65. GRADE (2020) GRADEpro Guideline DEvelopment Tool [program]. McMaster University, Hamilton

66. Whiting PF, Rutjes AW, Westwood ME et al (2011) QUADAS-2: a revised tool for the quality assessment of diagnostic accuracy studies. Ann Intern Med 155:529-536

67. Sterne JAC, Savovic J, Page MJ et al (2019) RoB 2: a revised tool for assessing risk of bias in randomised trials. BMJ 366:14898

68. Sterne JA, Hernan MA, Reeves BC et al (2016) ROBINS-I: a tool for assessing risk of bias in non-randomised studies of interventions. BMJ 355:i4919

69. Singh S, Allen AM, Wang Z, Prokop LJ, Murad MH, Loomba R (2015) Fibrosis progression in nonalcoholic fatty liver vs nonalcoholic steatohepatitis: a systematic review and meta-analysis of paired-biopsy studies. Clin Gastroenterol Hepatol 13:643-654 (e641-649; quiz e639-640)

70. Castera L, Friedrich-Rust M, Loomba R (2019) Noninvasive assessment of liver disease in patients with nonalcoholic fatty liver disease. Gastroenterology 156:1264-1281 (e1264)

71. Verhaegh P, Bavalia R, Winkens B, Masclee A, Jonkers D, Koek G (2018) Noninvasive tests do not accurately differentiate nonalcoholic steatohepatitis from simple steatosis: a systematic review and meta-analysis. Clin Gastroenterol Hepatol 16:837-861

72. Zheng KI, Liu WY, Pan XY et al (2020) Combined and sequential non-invasive approach to diagnosing non-alcoholic steatohepatitis in patients with non-alcoholic fatty liver disease and persistently normal alanine aminotransferase levels. BMJ Open Diabetes Res Care 8(1):e001174. https://doi.org/10.1136/ bmjdrc-2020-001174

73. Brunt EM, Janney CG, Di Bisceglie AM, Neuschwander-Tetri BA, Bacon BR (1999) Nonalcoholic steatohepatitis: a proposal for grading and staging the histological lesions. Am J Gastroenterol 94:2467-2474

74. Bedossa P, FLIP Pathology Consortium (2014) Utility and appropriateness of the fatty liver inhibition of progression (FLIP) algorithm and steatosis, activity, and fibrosis (SAF) score in the 
evaluation of biopsies of nonalcoholic fatty liver disease. Hepatology 60:565-575

75. Vilar-Gomez E, Chalasani N (2018) Non-invasive assessment of non-alcoholic fatty liver disease: clinical prediction rules and blood-based biomarkers. J Hepatol 68:305-315

76. Wong VW, Adams LA, de Ledinghen V, Wong GL, Sookoian S (2018) Noninvasive biomarkers in NAFLD and NASH-current progress and future promise. Nat Rev Gastroenterol Hepatol $15: 461-478$

77. Angulo P, Hui JM, Marchesini G et al (2007) The NAFLD fibrosis score: a noninvasive system that identifies liver fibrosis in patients with NAFLD. Hepatology 45:846-854

78. Sterling RK, Lissen E, Clumeck N et al (2006) Development of a simple noninvasive index to predict significant fibrosis in patients with HIV/HCV coinfection. Hepatology 43:1317-1325

79. Lin ZH, Xin YN, Dong QJ et al (2011) Performance of the aspartate aminotransferase-to-platelet ratio index for the staging of hepatitis C-related fibrosis: an updated meta-analysis. Hepatology 53:726-736

80. Harrison SA, Oliver D, Arnold HL, Gogia S, NeuschwanderTetri BA (2008) Development and validation of a simple NAFLD clinical scoring system for identifying patients without advanced disease. Gut 57:1441-1447

81. Xiao G, Zhu S, Xiao X, Yan L, Yang J, Wu G (2017) Comparison of laboratory tests, ultrasound, or magnetic resonance elastography to detect fibrosis in patients with nonalcoholic fatty liver disease: a meta-analysis. Hepatology 66:1486-1501

82. Sun W, Cui H, Li N et al (2016) Comparison of FIB-4 index, NAFLD fibrosis score and BARD score for prediction of advanced fibrosis in adult patients with non-alcoholic fatty liver disease: a meta-analysis study. Hepatol Res 46:862-870

83. McPherson S, Hardy T, Dufour JF et al (2017) Age as a confounding factor for the accurate non-invasive diagnosis of advanced NAFLD fibrosis. Am J Gastroenterol 112:740-751

84. Petta S, Wai-Sun Wong V, Bugianesi E et al (2019) Impact of obesity and alanine aminotransferase levels on the diagnostic accuracy for advanced liver fibrosis of noninvasive tools in patients with nonalcoholic fatty liver disease. Am J Gastroenterol d114:916-928

85. Joo SK, Kim W, Kim D et al (2018) Steatosis severity affects the diagnostic performances of noninvasive fibrosis tests in nonalcoholic fatty liver disease. Liver Int 38:331-341

86. Bertot LC, Jeffrey GP, de Boer B et al (2018) Diabetes impacts prediction of cirrhosis and prognosis by non-invasive fibrosis models in non-alcoholic fatty liver disease. Liver Int 38:1793-1802

87. Bril F, McPhaul MJ, Caulfield MP et al (2019) Performance of plasma biomarkers and diagnostic panels for nonalcoholic steatohepatitis and advanced fibrosis in patients with type 2 diabetes. Diabetes Care 43:290-297

88. Anstee QM, Lawitz EJ, Alkhouri N et al (2019) Noninvasive tests accurately identify advanced fibrosis due to NASH: baseline data from the STELLAR trials. Hepatology 70:1521-1530

89. Guillaume M, Moal V, Delabaudiere C et al (2019) Direct comparison of the specialised blood fibrosis tests FibroMeter(V2G) and Enhanced Liver Fibrosis score in patients with non-alcoholic fatty liver disease from tertiary care centres. Aliment Pharmacol Ther 50:1214-1222

90. Wong VW, Irles M, Wong GL et al (2019) Unified interpretation of liver stiffness measurement by M and XL probes in nonalcoholic fatty liver disease. Gut 68:2057-2064

91. Boursier J, Zarski JP, de Ledinghen V et al (2013) Determination of reliability criteria for liver stiffness evaluation by transient elastography. Hepatology 57:1182-1191

92. Eddowes PJ, Sasso M, Allison M et al (2019) Accuracy of FibroScan controlled attenuation parameter and liver stiffness measurement in assessing steatosis and fibrosis in patients with nonalcoholic fatty liver disease. Gastroenterology 156:1717-1730

93. Petta S, Maida M, Macaluso FS et al (2015) The severity of steatosis influences liver stiffness measurement in patients with nonalcoholic fatty liver disease. Hepatology 62:1101-1110

94. Petta S, Wong VW, Camma C et al (2017) Improved noninvasive prediction of liver fibrosis by liver stiffness measurement in patients with nonalcoholic fatty liver disease accounting for controlled attenuation parameter values. Hepatology 65:1145-1155

95. Karlas T, Petroff D, Sasso M et al (2018) Impact of controlled attenuation parameter on detecting fibrosis using liver stiffness measurement. Aliment Pharmacol Ther 47:989-1000

96. Hsu C, Caussy C, Imajo K et al (2019) Magnetic resonance vs transient elastography analysis of patients with nonalcoholic fatty liver disease: a systematic review and pooled analysis of individual participants. Clin Gastroenterol Hepatol 17:630-637 (e638)

97. Cassinotto C, Boursier J, de Ledinghen V et al (2016) Liver stiffness in nonalcoholic fatty liver disease: a comparison of supersonic shear imaging, FibroScan, and ARFI with liver biopsy. Hepatology 63:1817-1827

98. Petta S, Wong VW, Camma C et al (2017) Serial combination of non-invasive tools improves the diagnostic accuracy of severe liver fibrosis in patients with NAFLD. Aliment Pharmacol Ther 46:617-627

99. Petta S, Vanni E, Bugianesi E et al (2015) The combination of liver stiffness measurement and NAFLD fibrosis score improves the noninvasive diagnostic accuracy for severe liver fibrosis in patients with nonalcoholic fatty liver disease. Liver Int 35:1566-1573

100. Boursier J, de Ledinghen V, Leroy V et al (2017) A stepwise algorithm using an at-a-glance first-line test for the non-invasive diagnosis of advanced liver fibrosis and cirrhosis. J Hepatol 66:1158-1165

101. Srivastava A, Gailer R, Tanwar S et al (2019) Prospective evaluation of a primary care referral pathway for patients with nonalcoholic fatty liver disease. J Hepatol 71:371-378

102. Siddiqui MS, Yamada G, Vuppalanchi R et al (2019) Diagnostic accuracy of noninvasive fibrosis models to detect change in fibrosis stage. Clin Gastroenterol Hepatol 17:1877-1885 (e1875)

103. Angulo P, Bugianesi E, Bjornsson ES et al (2013) Simple noninvasive systems predict long-term outcomes of patients with nonalcoholic fatty liver disease. Gastroenterology 145:782-789 (e784)

104. Hagstrom H, Nasr P, Ekstedt M, Stal P, Hultcrantz R, Kechagias S (2019) Accuracy of noninvasive scoring systems in assessing risk of death and liver-related endpoints in patients with nonalcoholic fatty liver disease. Clin Gastroenterol Hepatol 17:11481156 (e1144)

105. Sebastiani G, Alshaalan R, Wong P et al (2015) Prognostic value of non-invasive fibrosis and steatosis tools, hepatic venous pressure gradient (HVPG) and histology in nonalcoholic steatohepatitis. PLoS One 10:e0128774

106. Onnerhag K, Hartman H, Nilsson PM, Lindgren S (2019) Noninvasive fibrosis scoring systems can predict future metabolic complications and overall mortality in non-alcoholic fatty liver disease (NAFLD). Scand J Gastroenterol 54:328-334

107. Boursier J, Vergniol J, Guillet A et al (2016) Diagnostic accuracy and prognostic significance of blood fibrosis tests and liver stiffness measurement by FibroScan in non-alcoholic fatty liver disease. J Hepatol 65:570-578

108. Munteanu M, Pais R, Peta V et al (2018) Long-term prognostic value of the FibroTest in patients with non-alcoholic fatty liver disease, compared to chronic hepatitis $\mathrm{C}, \mathrm{B}$, and alcoholic liver disease. Aliment Pharmacol Ther 48:1117-1127 
109. Kawamura Y, Arase Y, Ikeda K et al (2012) Large-scale longterm follow-up study of Japanese patients with non-alcoholic Fatty liver disease for the onset of hepatocellular carcinoma. Am J Gastroenterol 107:253-261

110. Shili-Masmoudi S, Wong GL, Hiriart JB et al (2019) Liver stiffness measurement predicts long-term survival and complications in non-alcoholic fatty liver disease. Liver Int 40:581-589

111. Petta S, Sebastiani G, Vigano M et al (2020) Monitoring occurrence of liver-related events and survival by transient elastography in patients with nonalcoholic fatty liver disease and compensated advanced chronic liver disease. Clin Gastroenterol Hepatol 19:806-815 (Epub ahead of Print, July 1)

112. Hagstrom $H$, Talback M, Andreasson A, Walldius G, Hammar N (2020) Repeated FIB-4 measurements can help identify individuals at risk of severe liver disease. J Hepatol 73:1023-1029

113. Eslam M, Valenti L, Romeo S (2018) Genetics and epigenetics of NAFLD and NASH: clinical impact. J Hepatol 68:268-279

114. Hyysalo J, Mannisto VT, Zhou Y et al (2014) A populationbased study on the prevalence of NASH using scores validated against liver histology. J Hepatol 60:839-846

115. Mancina RM, Dongiovanni P, Petta S et al (2016) The MBOAT7-TMC4 variant rs641738 increases risk of nonalcoholic fatty liver disease in individuals of European Descent. Gastroenterology 150:1219-1230 (e1216)

116. Abul-Husn NS, Cheng X, Li AH et al (2018) A protein-truncating HSD17B13 variant and protection from chronic liver disease. N Engl J Med 378:1096-1106

117. Valenti LV, Baselli GA (2018) Genetics of nonalcoholic fatty liver disease: a 2018 update. Curr Pharm Des 24:4566-4573

118. Grimaudo S, Pipitone RM, Pennisi G et al (2020) Association between PNPLA3 rs738409 C>G variant and liver-related outcomes in patients with nonalcoholic fatty liver disease. Clin Gastroenterol Hepatol 18:935-944 (e933)

119. Liu YL, Patman GL, Leathart JB et al (2013) Carriage of the PNPLA3 rs738409 $\mathrm{C}>\mathrm{G}$ polymorphism confers an increased risk of non-alcoholic fatty liver disease associated hepatocellular carcinoma. J Hepatol 61:75-81

120. Anstee QM, Liu YL, Day CP, Reeves HL (2015) Reply to: HCC and liver disease risk in homozygous PNPLA3 p.I148M carriers approach monogenic inheritance. J Hepatol 62:982-983

121. Pelusi S, Baselli G, Pietrelli A et al (2019) Rare pathogenic variants predispose to hepatocellular carcinoma in nonalcoholic fatty liver disease. Sci Rep 9:3682

122. Pillai S, Duvvuru S, Bhatnagar P et al (2018) The PNPLA3 I148M variant is associated with transaminase elevations in type 2 diabetes patients treated with basal insulin peglispro. Pharmacogenom J 18:487-493

123. Liu WY, Zheng KI, Pan XY et al (2020) Effect of PNPLA3 polymorphism on diagnostic performance of various noninvasive markers for diagnosing and staging nonalcoholic fatty liver disease. J Gastroenterol Hepatol 35:1057-1064

124. Marchesini G, Bugianesi E, Forlani G et al (2003) Nonalcoholic fatty liver, steatohepatitis, and the metabolic syndrome. Hepatology 37:917-923

125. Berentzen TL, Gamborg M, Holst C, Sorensen TI, Baker JL (2014) Body mass index in childhood and adult risk of primary liver cancer. J Hepatol 60:325-330

126. Zimmermann E, Gamborg M, Holst C, Baker JL, Sorensen TI, Berentzen TL (2015) Body mass index in school-aged children and the risk of routinely diagnosed non-alcoholic fatty liver disease in adulthood: a prospective study based on the Copenhagen School Health Records Register. BMJ Open 5:e006998

127. Hagstrom H, Stal P, Hultcrantz R, Hemmingsson T, Andreasson A (2016) Overweight in late adolescence predicts development of severe liver disease later in life: a 39years follow-up study. J Hepatol 65:363-368
128. Suzuki A, Angulo P, Lymp J et al (2005) Chronological development of elevated aminotransferases in a nonalcoholic population. Hepatology 41:64-71

129. Wong VW, Wong GL, Yeung DK et al (2015) Incidence of non-alcoholic fatty liver disease in Hong Kong: a population study with paired proton-magnetic resonance spectroscopy. J Hepatol 62:182-189

130. Tsuneto A, Hida A, Sera N et al (2010) Fatty liver incidence and predictive variables. Hypertens Res 33:638-643

131. Zelber-Sagi S, Lotan R, Shlomai A et al (2012) Predictors for incidence and remission of NAFLD in the general population during a seven-year prospective follow-up. J Hepatol $56: 1145-1151$

132. Moscatiello S, Di Luzio R, Bugianesi E et al (2011) Cognitive-behavioral treatment of non-alcoholic fatty liver disease: a propensity score-adjusted observational study. Obesity (Silver Spring) 19:763-770

133. Promrat K, Kleiner DE, Niemeier HM et al (2010) Randomized controlled trial testing the effects of weight loss on nonalcoholic steatohepatitis. Hepatology 51:121-129

134. Bellentani S, Dalle Grave R, Suppini A, Marchesini G, Fatty Liver Italian N (2008) Behavior therapy for nonalcoholic fatty liver disease: The need for a multidisciplinary approach. Hepatology 47:746-754

135. Marchesini G, Petta S, Dalle GR (2016) Diet, weight loss, and liver health in nonalcoholic fatty liver disease: pathophysiology, evidence, and practice. Hepatology 63:2032-2043

136. Mazzotti A, Caletti MT, Brodosi L et al (2018) An internetbased approach for lifestyle changes in patients with NAFLD: two-year effects on weight loss and surrogate markers. J Hepatol 69:1155-1163

137. Romero-Gomez M, Zelber-Sagi S, Trenell M (2017) Treatment of NAFLD with diet, physical activity and exercise. J Hepatol 67:829-846

138. Vilar-Gomez E, Calzadilla-Bertot L, Friedman SL et al (2017) Improvement in liver histology due to lifestyle modification is independently associated with improved kidney function in patients with non-alcoholic steatohepatitis. Aliment Pharmacol Ther 45:332-344

139. Vilar-Gomez E, Martinez-Perez Y, Calzadilla-Bertot L et al (2015) Weight loss through lifestyle modification significantly reduces features of nonalcoholic steatohepatitis. Gastroenterology 149:367-378 (e365; quiz e314-365)

140. Armstrong MJ, Gaunt P, Aithal GP et al (2016) Liraglutide safety and efficacy in patients with non-alcoholic steatohepatitis (LEAN): a multicentre, double-blind, randomised, placebocontrolled phase 2 study. Lancet 387:679-690

141. Wong VW, Chan RS, Wong GL et al (2013) Community-based lifestyle modification programme for non-alcoholic fatty liver disease: a randomized controlled trial. J Hepatol 59:536-542

142. Neuschwander-Tetri BA (2009) Lifestyle modification as the primary treatment of NASH. Clin Liver Dis 13:649-665

143. Marchesini G, Mazzella N, Forlani G (2015) Weight loss for a healthy liver. Gastroenterology 149:274-278

144. Petroni ML, Brodosi L, Barbanti FL, Di Domizio S, Petta S, Marchesini G (2020) Lifestyle changes for the treatment of nonalcoholic fatty liver disease-a 2015-19 update. Curr Pharma Des 26:1110-1118

145. Vilar-Gomez E, Athinarayanan SJ, Adams RN et al (2019) Post hoc analyses of surrogate markers of non-alcoholic fatty liver disease (NAFLD) and liver fibrosis in patients with type 2 diabetes in a digitally supported continuous care intervention: an open-label, non-randomised controlled study. BMJ Open 9:e023597 
146. Wong VW, Wong GL, Chan RS et al (2018) Beneficial effects of lifestyle intervention in non-obese patients with non-alcoholic fatty liver disease. J Hepatol 69:1349-1356

147. Kontogianni MD, Tileli N, Margariti A et al (2014) Adherence to the Mediterranean diet is associated with the severity of non-alcoholic fatty liver disease. Clin Nutr 33:678-683

148. Ryan MC, Itsiopoulos C, Thodis T et al (2013) The Mediterranean diet improves hepatic steatosis and insulin sensitivity in individuals with non-alcoholic fatty liver disease. J Hepatol 59:138-143

149. Gepner Y, Shelef I, Komy O et al (2019) The beneficial effects of Mediterranean diet over low-fat diet may be mediated by decreasing hepatic fat content. J Hepatol 71:379-388

150. Abid A, Taha O, Nseir W, Farah R, Grosovski M, Assy N (2009) Soft drink consumption is associated with fatty liver disease independent of metabolic syndrome. J Hepatol 51:918-924

151. Zelber-Sagi S, Nitzan-Kaluski D, Goldsmith R et al (2008) Role of leisure-time physical activity in nonalcoholic fatty liver disease: a population-based study. Hepatology 48:1791-1798

152. Ryu S, Chang Y, Jung HS et al (2015) Relationship of sitting time and physical activity with non-alcoholic fatty liver disease. J Hepatol 63:1229-1237

153. St George A, Bauman A, Johnston A, Farrell G, Chey T, George $J$ (2009) Independent effects of physical activity in patients with nonalcoholic fatty liver disease. Hepatology 50:68-76

154. Hashida R, Kawaguchi T, Bekki M et al (2017) Aerobic vs. resistance exercise in non-alcoholic fatty liver disease: a systematic review. J Hepatol 66:142-152

155. Keating SE, George J, Johnson NA (2015) The benefits of exercise for patients with non-alcoholic fatty liver disease. Expert Rev Gastroenterol Hepatol 9:1247-1250

156. Sookoian S, Castano GO, Pirola CJ (2014) Modest alcohol consumption decreases the risk of non-alcoholic fatty liver disease: a meta-analysis of 43175 individuals. Gut 63:530-532

157. Dunn W, Sanyal AJ, Brunt EM et al (2012) Modest alcohol consumption is associated with decreased prevalence of steatohepatitis in patients with non-alcoholic fatty liver disease (NAFLD). J Hepatol 57:384-391

158. Chang Y, Cho YK, Kim Y et al (2019) Nonheavy drinking and worsening of noninvasive fibrosis markers in nonalcoholic fatty liver disease: a cohort study. Hepatology 69:64-75

159. Chang Y, Ryu S, Kim Y et al (2020) Low levels of alcohol consumption, obesity, and development of fatty liver with and without evidence of advanced fibrosis. Hepatology 71:861-873

160. Ajmera V, Belt P, Wilson LA et al (2018) Among patients with nonalcoholic fatty liver disease, modest alcohol use is associated with less improvement in histologic steatosis and steatohepatitis. Clin Gastroenterol Hepatol 16:1511-1520 (e1515)

161. Xu L, Xie J, Chen S et al (2020) Light-to-moderate alcohol consumption is associated with increased risk of type 2 diabetes in individuals with nonalcoholic fatty liver disease: a nine-year cohort study. Am J Gastroenterol 115:876-884

162. VanWagner LB, Ning H, Allen NB et al (2017) Alcohol use and cardiovascular disease risk in patients with nonalcoholic fatty liver disease. Gastroenterology 153:1260-1272 (e1263)

163. Aberg F, Puukka P, Salomaa V et al (2020) Risks of light and moderate alcohol use in fatty liver disease: follow-up of population cohorts. Hepatology 71:835-848

164. Hajifathalian K, Torabi Sagvand B, McCullough AJ (2019) Effect of alcohol consumption on survival in nonalcoholic fatty liver disease: a national prospective cohort study. Hepatology 70:511-521

165. Ascha MS, Hanouneh IA, Lopez R, Tamimi TA, Feldstein AF, Zein NN (2010) The incidence and risk factors of hepatocellular carcinoma in patients with nonalcoholic steatohepatitis. Hepatology $51: 1972-1978$

166. The Diabetes Prevention Program Research Group (2002) The Diabetes Prevention Program (DPP): description of lifestyle intervention. Diabetes Care 25:2165-2171

167. Look AHEAD Research Group, Wing RR, Bolin P et al (2013) Cardiovascular effects of intensive lifestyle intervention in type 2 diabetes. N Engl J Med 369:145-154

168. Burza MA, Romeo S, Kotronen A et al (2013) Long-term effect of bariatric surgery on liver enzymes in the Swedish Obese Subjects (SOS) study. PLoS One 8:e60495

169. Sjostrom L, Peltonen M, Jacobson P et al (2014) Association of bariatric surgery with long-term remission of type 2 diabetes and with microvascular and macrovascular complications. JAMA 311:2297-2304

170. Lassailly G, Caiazzo R, Buob D et al (2015) Bariatric surgery reduces features of nonalcoholic steatohepatitis in morbidly obese patients. Gastroenterology 149:379-388 (quiz e315-376)

171. Lassailly G, Caiazzo R, Ntandja-Wandji LC et al (2020) Bariatric surgery provides long-term resolution of nonalcoholic steatohepatitis and regression of fibrosis. Gastroenterology 159:1290-1301

172. Sjostrom L, Peltonen M, Jacobson P et al (2012) Bariatric surgery and long-term cardiovascular events. JAMA 307:56-65

173. Mingrone G, Panunzi S, De Gaetano A et al (2012) Bariatric surgery versus conventional medical therapy for type 2 diabetes. N Engl J Med 366:1577-1585

174. Sjoholm K, Pajunen P, Jacobson P et al (2015) Incidence and remission of type 2 diabetes in relation to degree of obesity at baseline and 2 year weight change: the Swedish Obese Subjects (SOS) study. Diabetologia 58:1448-1453

175. Klebanoff MJ, Corey KE, Chhatwal J, Kaplan LM, Chung RT, Hur C (2017) Bariatric surgery for nonalcoholic steatohepatitis: a clinical and cost-effectiveness analysis. Hepatology 65:1156-1164

176. Chalasani N, Younossi Z, Lavine JE et al (2018) The diagnosis and management of nonalcoholic fatty liver disease: practice guidance from the American Association for the Study of Liver Diseases. Hepatology 67:328-357

177. Rinella ME, Tacke F, Sanyal AJ, Anstee QM, participants of the AASLD EASL Workshop (2019) Report on the AASLD/ EASL joint workshop on clinical trial endpoints in NAFLD. $J$ Hepatol 71:823-833

178. Belfort R, Harrison SA, Brown K et al (2006) A placebocontrolled trial of pioglitazone in subjects with nonalcoholic steatohepatitis. N Engl J Med 355:2297-2307

179. Aithal GP, Thomas JA, Kaye PV et al (2008) Randomized, placebo-controlled trial of pioglitazone in nondiabetic subjects with nonalcoholic steatohepatitis. Gastroenterology 135:1176-1184

180. Ratziu V, Giral P, Jacqueminet S et al (2008) Rosiglitazone for nonalcoholic steatohepatitis: one-year results of the randomized placebo-controlled Fatty Liver Improvement with Rosiglitazone Therapy (FLIRT) Trial. Gastroenterology 135:100-110

181. Sanyal AJ, Chalasani N, Kowdley KV et al (2010) Pioglitazone, vitamin E, or placebo for nonalcoholic steatohepatitis. N Engl J Med 362:1675-1685

182. Torres DM, Jones FJ, Shaw JC, Williams CD, Ward JA, Harrison SA (2011) Rosiglitazone versus rosiglitazone and metformin versus rosiglitazone and losartan in the treatment of nonalcoholic steatohepatitis in humans: a 12-month randomized, prospective, open- label trial. Hepatology 54:1631-1639

183. Sharma BC, Kumar A, Garg V, Reddy RS, Sakhuja P, Sarin SK (2012) A randomized controlled trial comparing efficacy of pentoxifylline and pioglitazone on metabolic factors and liver 
histology in patients with non-alcoholic steatohepatitis. J Clin Exp Hepatol 2:333-337

184. Razavizade M, Jamali R, Arj A, Matini SM, Moraveji A, Taherkhani E (2013) The effect of pioglitazone and metformin on liver function tests, insulin resistance, and liver fat content in nonalcoholic Fatty liver disease: a randomized double blinded clinical trial. Hepat Mon 13:e9270

185. Cusi K, Orsak B, Bril F et al (2016) Long-term pioglitazone treatment for patients with nonalcoholic steatohepatitis and prediabetes or type 2 diabetes mellitus: a randomized trial. Ann Intern Med 165:305-315

186. Musso G, Cassader M, Paschetta E, Gambino R (2017) Pioglitazone for advanced fibrosis in nonalcoholic steatohepatitis: new evidence, new challenges. Hepatology 65:1058-1061

187. Yen FS, Yang YC, Hwu CM et al (2020) Liver-related long-term outcomes of thiazolidinedione use in persons with type 2 diabetes. Liver Int 40:1089-1097

188. Dormandy JA, Charbonnel B, Eckland DJ et al (2005) Secondary prevention of macrovascular events in patients with type 2 diabetes in the PROactive Study (PROspective pioglitAzone Clinical Trial In macroVascular Events): a randomised controlled trial. Lancet 366:1279-1289

189. Kernan WN, Viscoli CM, Furie KL et al (2016) Pioglitazone after ischemic stroke or transient ischemic attack. N Engl J Med 374:1321-1331

190. Lewis JD, Habel LA, Quesenberry CP et al (2015) Pioglitazone use and risk of bladder cancer and other common cancers in persons with diabetes. JAMA 314:265-277

191. Billington EO, Grey A, Bolland MJ (2015) The effect of thiazolidinediones on bone mineral density and bone turnover: systematic review and meta-analysis. Diabetologia 58:2238-2246

192. Liao HW, Saver JL, Wu YL, Chen TH, Lee M, Ovbiagele B (2017) Pioglitazone and cardiovascular outcomes in patients with insulin resistance, pre-diabetes and type 2 diabetes: a systematic review and meta-analysis. BMJ Open 7:e013927

193. Mahady SE, Wong G, Craig JC, George J (2012) Pioglitazone and vitamin $\mathrm{E}$ for nonalcoholic steatohepatitis: a cost utility analysis. Hepatology 56:2172-2179

194. Hoofnagle JH, Van Natta ML, Kleiner DE et al (2013) Vitamin $\mathrm{E}$ and changes in serum alanine aminotransferase levels in patients with non-alcoholic steatohepatitis. Aliment Pharmacol Ther 38:134-143

195. Sato K, Gosho M, Yamamoto T et al (2015) Vitamin E has a beneficial effect on nonalcoholic fatty liver disease: a meta-analysis of randomized controlled trials. Nutrition 31:923-930

196. Xu R, Tao A, Zhang S, Deng Y, Chen G (2015) Association between vitamin $\mathrm{E}$ and non-alcoholic steatohepatitis: a metaanalysis. Int J Clin Exp Med 8:3924-3934

197. Bril F, Biernacki DM, Kalavalapalli S et al (2019) Role of vitamin $\mathrm{E}$ for nonalcoholic steatohepatitis in patients with type 2 diabetes: a randomized controlled trial. Diabetes Care 42:1481-1488

198. Vilar-Gomez E, Vuppalanchi R, Gawrieh S et al (2018) Vitamin E improves transplant-free survival and hepatic decompensation among patients with nonalcoholic steatohepatitis and advanced fibrosis. Hepatology 71:495-509

199. Bjelakovic G, Nikolova D, Gluud LL, Simonetti RG, Gluud C (2007) Mortality in randomized trials of antioxidant supplements for primary and secondary prevention: systematic review and meta-analysis. JAMA 297:842-857

200. Schurks M, Glynn RJ, Rist PM, Tzourio C, Kurth T (2010) Effects of vitamin $\mathrm{E}$ on stroke subtypes: meta-analysis of randomised controlled trials. BMJ 341:c5702

201. Klein EA, Thompson IM Jr, Tangen CM et al (2011) Vitamin $\mathrm{E}$ and the risk of prostate cancer: the selenium and vitamin $\mathrm{E}$ cancer prevention trial (SELECT). JAMA 306:1549-1556
202. Dufour JF, Oneta CM, Gonvers JJ et al (2006) Randomized placebo-controlled trial of ursodeoxycholic acid with vitamin E in nonalcoholic steatohepatitis. Clin Gastroenterol Hepatol $4: 1537-1543$

203. Lindor KD, Kowdley KV, Heathcote EJ et al (2004) Ursodeoxycholic acid for treatment of nonalcoholic steatohepatitis: results of a randomized trial. Hepatology 39:770-778

204. Leuschner UF, Lindenthal B, Herrmann G et al (2010) High-dose ursodeoxycholic acid therapy for nonalcoholic steatohepatitis: a double-blind, randomized, placebo-controlled trial. Hepatology 52:472-479

205. Ratziu V, de Ledinghen V, Oberti F et al (2011) A randomized controlled trial of high-dose ursodesoxycholic acid for nonalcoholic steatohepatitis. J Hepatol 54:1011-1019

206. Younossi ZM, Ratziu V, Loomba R et al (2019) Obeticholic acid for the treatment of non-alcoholic steatohepatitis: interim analysis from a multicentre, randomised, placebo-controlled phase 3 trial. Lancet 394:2184-2196

207. Neuschwander-Tetri BA, Loomba R, Sanyal AJ et al (2015) Farnesoid X nuclear receptor ligand obeticholic acid for noncirrhotic, non-alcoholic steatohepatitis (FLINT): a multicentre, randomised, placebo-controlled trial. Lancet 385:956-965

208. Intercept Pharmaceuticals: Update on Intercept's NDA Submission to the FDA (2020). In: Globe Newswire. https://ir. interceptpharma.com/news-releases/news-release-details/inter cept-receives-complete-response-letter-fda-obeticholic-acid

209. Bugianesi E, Gentilcore E, Manini R et al (2005) A randomized controlled trial of metformin versus vitamin $\mathrm{E}$ or prescriptive diet in nonalcoholic fatty liver disease. Am J Gastroenterol 100:1082-1090

210. Haukeland JW, Konopski Z, Eggesbo HB et al (2009) Metformin in patients with non-alcoholic fatty liver disease: a randomized, controlled trial. Scand J Gastroenterol 44:853-860

211. Lavine JE, Schwimmer JB, Van Natta ML et al (2011) Effect of vitamin $\mathrm{E}$ or metformin for treatment of nonalcoholic fatty liver disease in children and adolescents: the TONIC randomized controlled trial. JAMA 305:1659-1668

212. Omer Z, Cetinkalp S, Akyildiz M et al (2010) Efficacy of insulin-sensitizing agents in nonalcoholic fatty liver disease. Eur $\mathbf{J}$ Gastroenterol Hepatol 22:18-23

213. Rana H, Yadav SS, Reddy HD, Singhal S, Singh DK, Usman K (2016) Comparative effect of insulin sensitizers and statin on metabolic profile and ultrasonographical score in non alcoholic fatty liver disease. J Clin Diagn Res 10:OC19-OC23

214. Zhang ZJ, Zheng ZJ, Shi R, Su Q, Jiang Q, Kip KE (2012) Metformin for liver cancer prevention in patients with type 2 diabetes: a systematic review and meta-analysis. J Clin Endocrinol Metab 97:2347-2353

215. Cui J, Philo L, Nguyen P et al (2016) Sitagliptin vs. placebo for non-alcoholic fatty liver disease: a randomized controlled trial. J Hepatol 65:369-376

216. Macauley M, Hollingsworth KG, Smith FE et al (2015) Effect of vildagliptin on hepatic steatosis. J Clin Endocrinol Metab 100:1578-1585

217. Deng XL, Ma R, Zhu HX, Zhu J (2017) Short article: a randomized-controlled study of sitagliptin for treating diabetes mellitus complicated by nonalcoholic fatty liver disease. Eur J Gastroenterol Hepatol 29:297-301

218. Yan J, Yao B, Kuang H et al (2019) Liraglutide, sitagliptin, and insulin glargine added to metformin: the effect on body weight and intrahepatic lipid in patients with type 2 diabetes mellitus and nonalcoholic fatty liver disease. Hepatology 69:2414-2426

219. American Diabetes Association (2019) 9. Pharmacologic approaches to glycemic treatment: Standards of medical care in diabetes-2019. Diabetes Care 42:S90-S102 
220. Armstrong MJ, Houlihan DD, Rowe IA et al (2013) Safety and efficacy of liraglutide in patients with type 2 diabetes and elevated liver enzymes: individual patient data meta-analysis of the LEAD program. Aliment Pharmacol Ther 37:234-242

221. Shao N, Kuang HY, Hao M, Gao XY, Lin WJ, Zou W (2014) Benefits of exenatide on obesity and non-alcoholic fatty liver disease with elevated liver enzymes in patients with type 2 diabetes. Diabetes Metab Res Rev 30:521-529

222. Dutour A, Abdesselam I, Ancel P et al (2016) Exenatide decreases liver fat content and epicardial adipose tissue in patients with obesity and type 2 diabetes: a prospective randomized clinical trial using magnetic resonance imaging and spectroscopy. Diabetes Obes Metab 18:882-891

223. Frossing S, Nylander M, Chabanova E et al (2018) Effect of liraglutide on ectopic fat in polycystic ovary syndrome: a randomized clinical trial. Diabetes Obes Metab 20:215-218

224. Feng W, Gao C, Bi Y et al (2017) Randomized trial comparing the effects of gliclazide, liraglutide, and metformin on diabetes with non-alcoholic fatty liver disease. J Diabetes 9:800-809

225. Newsome P, Francque S, Harrison S et al (2019) Effect of semaglutide on liver enzymes and markers of inflammation in subjects with type 2 diabetes and/or obesity. Aliment Pharmacol Ther 50:193-203

226. Newsome PN, Buchholtz K, Cusi K et al (2020) A placebocontrolled trial of subcutaneous semaglutide in nonalcoholic steatohepatitis. N Engl J Med 384:1113-1124 (Epub ahead of Print, Nov 13)

227. Kristensen SL, Rorth R, Jhund PS et al (2019) Cardiovascular, mortality, and kidney outcomes with GLP-1 receptor agonists in patients with type 2 diabetes: a systematic review and metaanalysis of cardiovascular outcome trials. Lancet Diabetes Endocrinol 7:776-785

228. Sattar N, Fitchett D, Hantel S, George JT, Zinman B (2018) Empagliflozin is associated with improvements in liver enzymes potentially consistent with reductions in liver fat: results from randomised trials including the EMPA-REG OUTCOME(R) trial. Diabetologia 61:2155-2163

229. Ito D, Shimizu S, Inoue K et al (2017) Comparison of ipragliflozin and pioglitazone effects on nonalcoholic fatty liver disease in patients with type 2 diabetes: a randomized, 24-week, open-label, active-controlled trial. Diabetes Care 40:1364-1372

230. Kuchay MS, Krishan S, Mishra SK et al (2018) Effect of empagliflozin on liver fat in patients with type 2 diabetes and nonalcoholic fatty liver disease: a randomized controlled trial (E-LIFT trial). Diabetes Care 41:1801-1808

231. Eriksson JW, Lundkvist P, Jansson PA et al (2018) Effects of dapagliflozin and n-3 carboxylic acids on non-alcoholic fatty liver disease in people with type 2 diabetes: a double-blind randomised placebo-controlled study. Diabetologia 61:1923-1934

232. Bolinder J, Ljunggren O, Kullberg J et al (2012) Effects of dapagliflozin on body weight, total fat mass, and regional adipose tissue distribution in patients with type 2 diabetes mellitus with inadequate glycemic control on metformin. J Clin Endocrinol Metab 97:1020-1031

233. Cusi K, Bril F, Barb D et al (2019) Effect of canagliflozin treatment on hepatic triglyceride content and glucose metabolism in patients with type 2 diabetes. Diabetes Obes Metab 21:812-821

234. Leiter LA, Forst T, Polidori D, Balis DA, Xie J, Sha S (2016) Effect of canagliflozin on liver function tests in patients with type 2 diabetes. Diabetes Metab 42:25-32

235. Wilding JP, Charpentier G, Hollander P et al (2013) Efficacy and safety of canagliflozin in patients with type 2 diabetes mellitus inadequately controlled with metformin and sulphonylurea: a randomised trial. Int J Clin Pract 67:1267-1282

236. Shimizu M, Suzuki K, Kato K et al (2019) Evaluation of the effects of dapagliflozin, a sodium-glucose co-transporter-2 inhibitor, on hepatic steatosis and fibrosis using transient elastography in patients with type 2 diabetes and non-alcoholic fatty liver disease. Diabetes Obes Metab 21:285-292

237. Bolinder J, Ljunggren O, Johansson L et al (2014) Dapagliflozin maintains glycaemic control while reducing weight and body fat mass over 2 years in patients with type 2 diabetes mellitus inadequately controlled on metformin. Diabetes Obes Metab 16:159-169

238. Kluger AY, Tecson KM, Lee AY et al (2019) Class effects of SGLT2 inhibitors on cardiorenal outcomes. Cardiovasc Diabetol 18:99

239. Haldar D, Kern B, Hodson J et al (2019) Outcomes of liver transplantation for non-alcoholic steatohepatitis: a European Liver Transplant Registry study. J Hepatol 71:313-322

240. Wang X, Li J, Riaz DR, Shi G, Liu C, Dai Y (2014) Outcomes of liver transplantation for nonalcoholic steatohepatitis: a systematic review and meta-analysis. Clin Gastroenterol Hepatol 12:394-402 (e391)

241. Tsochatzis E, Coilly A, Nadalin S et al (2019) International Liver Transplantation consensus statement on end-stage liver disease due to nonalcoholic steatohepatitis and liver transplantation. Transplantation 103:45-56

242. Stine JG, Wentworth BJ, Zimmet A et al (2018) Systematic review with meta-analysis: risk of hepatocellular carcinoma in non-alcoholic steatohepatitis without cirrhosis compared to other liver diseases. Aliment Pharmacol Ther 48:696-703

243. Kulik L, El-Serag HB (2019) Epidemiology and management of hepatocellular carcinoma. Gastroenterology 156:477-491 (e471)

244. An J, Shim JH, Kim SO et al (2014) Prevalence and prediction of coronary artery disease in patients with liver cirrhosis: a registrybased matched case-control study. Circulation 130:1353-1362

245. Patel SS, Nabi E, Guzman L et al (2018) Coronary artery disease in decompensated patients undergoing liver transplantation evaluation. Liver Transpl 24:333-342

246. Konerman MA, Fritze D, Weinberg RL, Sonnenday CJ, Sharma $P$ (2017) Incidence of and risk assessment for adverse cardiovascular outcomes after liver transplantation: a systematic review. Transplantation 101:1645-1657

247. Yotti R, Ripoll C, Bermejo J, Banares R (2018) Cardiac function, a key component in evaluation for liver transplant. Liver Transpl $24: 7-8$

248. Carey WD, Dumot JA, Pimentel RR et al (1995) The prevalence of coronary artery disease in liver transplant candidates over age 50. Transplantation 59:859-864

249. Plotkin JS, Scott VL, Pinna A, Dobsch BP, De Wolf AM, Kang Y (1996) Morbidity and mortality in patients with coronary artery disease undergoing orthotopic liver transplantation. Liver Transpl Surg 2:426-430

250. Hayes SW, De Lorenzo A, Hachamovitch R et al (2003) Prognostic implications of combined prone and supine acquisitions in patients with equivocal or abnormal supine myocardial perfusion SPECT. J Nucl Med 44:1633-1640

251. Senzolo M, Bassanello M, Graziotto A et al (2008) Microvascular autonomic dysfunction may justify false-positive stress myocardial perfusion imaging in patients with liver cirrhosis undergoing liver transplantation. Transplant Proc 40:1916-1917

252. Germani G, Laryea M, Rubbia-Brandt L et al (2019) Management of recurrent and de novo NAFLD/NASH after liver transplantation. Transplantation 103:57-67

253. Fleisher LA, Fleischmann KE, Auerbach AD et al (2014) 2014 ACC/AHA guideline on perioperative cardiovascular evaluation and management of patients undergoing noncardiac surgery: executive summary: a report of the American College of Cardiology/American Heart Association Task Force on Practice Guidelines. Circulation 130:2215-2245 
254. Chalasani N, Younossi Z, Lavine JE et al (2012) The diagnosis and management of non-alcoholic fatty liver disease: practice Guideline by the American Association for the Study of Liver Diseases, American College of Gastroenterology, and the American Gastroenterological Association. Hepatology 55:2005-2023

255. Nair S, Verma S, Thuluvath PJ (2002) Obesity and its effect on survival in patients undergoing orthotopic liver transplantation in the United States. Hepatology 35:105-109

256. Ratziu V, Ghabril M, Romero-Gomez M, Svegliati-Baroni G (2019) Recommendations for management and treatment of nonalcoholic steatohepatitis. Transplantation 103:28-38

257. Younossi ZM, Stepanova M, Saab S et al (2014) The impact of type 2 diabetes and obesity on the long-term outcomes of more than 85000 liver transplant recipients in the US. Aliment Pharmacol Ther 40:686-694

258. Mosko JD, Nguyen GC (2011) Increased perioperative mortality following bariatric surgery among patients with cirrhosis. Clin Gastroenterol Hepatol 9:897-901

259. Lin MY, Tavakol MM, Sarin A et al (2013) Laparoscopic sleeve gastrectomy is safe and efficacious for pretransplant candidates. Surg Obes Relat Dis 9:653-658

260. Takata MC, Campos GM, Ciovica R et al (2008) Laparoscopic bariatric surgery improves candidacy in morbidly obese patients awaiting transplantation. Surg Obes Relat Dis 4:159-164 (discussion 164-155)

261. Dziodzio T, Biebl M, Ollinger R, Pratschke J, Denecke C (2017) The role of bariatric surgery in abdominal organ transplantationthe next big challenge? Obes Surg 27:2696-2706

262. Heimbach JK, Watt KD, Poterucha JJ et al (2013) Combined liver transplantation and gastric sleeve resection for patients with medically complicated obesity and end-stage liver disease. Am J Transplant 13:363-368

263. Bedogni G, Bellentani S, Miglioli L et al (2006) The Fatty Liver Index: a simple and accurate predictor of hepatic steatosis in the general population. BMC Gastroenterol 6:33

264. Fedchuk L, Nascimbeni F, Pais R et al (2014) Performance and limitations of steatosis biomarkers in patients with nonalcoholic fatty liver disease. Aliment Pharmacol Ther 40:1209-1222

265. Hernaez R, Lazo M, Bonekamp S et al (2011) Diagnostic accuracy and reliability of ultrasonography for the detection of fatty liver: a meta-analysis. Hepatology 54:1082-1090

266. Ajmera V, Park CC, Caussy C et al (2018) Magnetic resonance imaging proton density fat fraction associates with progression of fibrosis in patients with nonalcoholic fatty liver disease. Gastroenterology 155:307-310 (e302)

267. Ryan CK, Johnson LA, Germin BI, Marcos A (2002) One hundred consecutive hepatic biopsies in the workup of living donors for right lobe liver transplantation. Liver Transpl 8:1114-1122

268. Lee SS, Park SH (2014) Radiologic evaluation of nonalcoholic fatty liver disease. World J Gastroenterol 20:7392-7402

269. Gu J, Liu S, Du S et al (2019) Diagnostic value of MRI-PDFF for hepatic steatosis in patients with non-alcoholic fatty liver disease: a meta-analysis. Eur Radiol 29:3564-3573
270. Loomba R (2018) Role of imaging-based biomarkers in NAFLD: Recent advances in clinical application and future research directions. J Hepatol 68:296-304

271. Pu K, Wang Y, Bai S et al (2019) Diagnostic accuracy of controlled attenuation parameter (CAP) as a non-invasive test for steatosis in suspected non-alcoholic fatty liver disease: a systematic review and meta-analysis. BMC Gastroenterol 19:51

272. Petroff D, Blank V, Newsome PN et al (2021) Assessment of hepatic steatosis by controlled attenuation parameter using the $\mathrm{M}$ and XL probes: an individual patient data meta-analysis. Lancet Gastroenterol Hepatol 6:185-198

273. Caussy C, Alquiraish MH, Nguyen P et al (2018) Optimal threshold of controlled attenuation parameter with MRI-PDFF as the gold standard for the detection of hepatic steatosis. Hepatology 67:1348-1359

274. Chan WK, Nik Mustapha NR, Mahadeva S, Wong VW, Cheng JY, Wong GL (2018) Can the same controlled attenuation parameter cut-offs be used for M and XL probes for diagnosing hepatic steatosis? J Gastroenterol Hepatol 33:1787-1794

275. Karlas T, Petroff D, Sasso M et al (2017) Individual patient data meta-analysis of controlled attenuation parameter (CAP) technology for assessing steatosis. J Hepatol 66:1022-1030

276. Wilson JMG, Jungner G (1968) Principles and practice of screening for disease. World Health Organization, Geneva

277. Nascimbeni F, Pais R, Bellentani S et al (2013) From NAFLD in clinical practice to answers from guidelines. J Hepatol 59:859-871

278. Kanwal F, Kramer J, Li L et al (2020) Effect of metabolic traits on the risk of cirrhosis and hepatocellular cancer in non-alcoholic fatty liver disease. Hepatology 71:808-819

279. Usher-Smith JA, Sharp SJ, Griffin SJ (2016) The spectrum effect in tests for risk prediction, screening, and diagnosis. BMJ 353:i3139

280. Harris R, Harman DJ, Card TR, Aithal GP, Guha IN (2017) Prevalence of clinically significant liver disease within the general population, as defined by non-invasive markers of liver fibrosis: a systematic review. Lancet Gastroenterol Hepatol 2:288-297

281. Standing HC, Jarvis H, Orr J et al (2018) GPs' experiences and perceptions of early detection of liver disease: a qualitative study in primary care. Br J Gen Pract 68:e743-e749

282. Srivastava A, Jong S, Gola A et al (2019) Cost-comparison analysis of FIB-4, ELF and fibroscan in community pathways for nonalcoholic fatty liver disease. BMC Gastroenterol 19:122

283. Petroni ML, Brodosi L, Bugianesi E, Marchesini G (2021) Management of non-alcoholic fatty liver disease. BMJ 372:m4747

Publisher's Note Springer Nature remains neutral with regard to jurisdictional claims in published maps and institutional affiliations. 